Supporting Information

\title{
Dynamical Observation and Detailed Description of Catalysts under Strong Metal-Support Interaction
}

\author{
Shuyi Zhang, ${ }^{1,2}$ Philipp N. Plessow, ${ }^{3,4}$ § Joshua J. Willis, ${ }^{4}$ Sheng Dai, ${ }^{1,2}$ Mingjie Xu, ${ }^{1,2}$ \\ George W. Graham, ${ }^{1,2}$ Matteo Cargnello, ${ }^{4}$ Frank Abild-Pedersen, ${ }^{3}$ and Xiaoqing Pan ${ }^{1,5^{*}}$
}

${ }^{1}$ Department of Chemical Engineering and Materials Science, University of California Irvine, Irvine, California 92697, USA.

${ }^{2}$ Department of Materials Science and Engineering, University of Michigan, Ann Arbor, Michigan 48109, USA.

${ }^{3}$ SUNCAT Center for Interface Science and Catalysis, SLAC National Accelerator Laboratory, Menlo Park, California 94025, USA.

${ }^{4}$ Department of Chemical Engineering and SUNCAT Center for Interface Science and Catalysis, Stanford University, Stanford, California 94305, USA.

${ }^{5}$ Department of Physics and Astronomy, University of California - Irvine, Irvine, California 92697, USA.

$\S$ Present address: Institute of Catalysis Research and Technology (IKFT), Hermann-vonHelmholtz-Platz 1, D-76344 Eggenstein-Leopoldshafen, Germany.

*Corresponding Author, Email: xiaoqing.pan@uci.edu 


\section{Supplementary Materials:}

Materials and Methods

Figures S1-S20

Table S1-S3 


\section{Supplementary Materials}

\section{Materials and Methods}

Synthesis of $\mathrm{Pd} / \mathrm{TiO}_{2}, \mathrm{Pt} / \mathrm{TiO}$, $\mathrm{Au} / \mathrm{TiO}_{2}$ samples

The supported catalyst systems were prepared by deposition of pre-formed metal nanocrystals onto commercial titania P25 (Sigma-Aldrich). Pd and Pt nanocrystals were

synthesized according to reference ${ }^{1}$, whereas Au nanocrystals followed reference ${ }^{2}$. The conditions were:

\section{Pd nanocrystals}

A mixture of $0.25 \mathrm{mmol} \operatorname{Pd}(\mathrm{acac})_{2}, 2.5 \mathrm{mmol}$ oleylamine, $1.25 \mathrm{mmol}$ trioctylphosphine, $1.25 \mathrm{mmol}$ oleic acid, $6.6 \mathrm{~mL}$ 1-octadecene, $3.4 \mathrm{~mL}$ 1-tetradecene, reaction at $290{ }^{\circ} \mathrm{C}$ for 15 minutes.

\section{Pt nanocrystals}

A mixture of $0.25 \mathrm{mmol} \mathrm{Pt}(\mathrm{acac})_{2}, 2.0 \mathrm{mmol}$ oleylamine, $0.5 \mathrm{mmol}$ trioctylphosphine, 4.0 mmol oleic acid, $10 \mathrm{~mL}$ of trioctylamine were reacted at $30{ }^{\circ} \mathrm{C}$ for 30 minutes.

\section{Au nanocrystals}

A mixture of $100 \mathrm{mg} \mathrm{HAuCl}_{4}, 10 \mathrm{~mL}$ oleylamine (80-90\%, Acros), $10 \mathrm{~mL}$ tetraline, were dissolved and reacted at room temperature with a solution of $0.5 \mathrm{mmol}$ of tributylamine borane complex (Sigma-Aldrich) in $1 \mathrm{~mL}$ oleylamine and $1 \mathrm{~mL}$ tetraline.

The purified nanocrystals dissolved in hexanes at appropriate concentrations were added to a stirred solution of titania $\mathrm{P} 25$ in toluene $(40 \mathrm{~mL})$ in order to obtain a final loading of 0.5 wt. $\%$ in metal. The samples were left stirring for 30 minutes. Powders were collected by centrifugation, dried overnight and the organic ligands removed following a fast thermal treatment in a furnace at $700{ }^{\circ} \mathrm{C}$ for 30 seconds. 


\section{Characterization techniques}

In situ TEM was conducted on a JEOL 3100-R05 microscope with double Cs-correctors operated at $300 \mathrm{kV}$ using the Protochips Atmosphere system as described before ${ }^{3}$, and EELS data was acquired with Gatan \#965 Quantum Imaging Filter (GIF) for electron energy loss spectroscopy and imaging. The purity of the gases used in the in situ experiment was $99.9995 \%$. All reported temperatures are based on the Protochips calibration.

\section{DFT calculation}

DFT-calculations have been carried out with Quantum Espresso ${ }^{4}$ using ultrasoft pseudopotentials ${ }^{5}$ and Fermi-Dirac smearing with $\mathrm{k}_{\mathrm{B}} T=0.1 \mathrm{eV}$, except for gas-phase molecules, where integer occupation numbers have been enforced. The energy cut-off for the plane wave expansion of wave function (density) was $500 \mathrm{eV}(5000 \mathrm{eV})$. We have used $\mathrm{H}_{2}$ and $\mathrm{H}_{2} \mathrm{O}$ as reference gas-phase molecules and the $\mathrm{O}_{2}$-reference was obtained using its experimental binding energy corrected by the zero-point energy: $\mathrm{E}\left(\mathrm{O}_{2}\right)=\mathrm{E}\left(\mathrm{H}_{2} \mathrm{O}\right)-\mathrm{E}\left(\mathrm{H}_{2}\right)$ $+2.75 \mathrm{eV}$. $\Gamma$-centered k-point sampling was used in all cases. Generally we employed a kpoint-density roughly corresponding to $(12 \times 12 \times 1)$ per $(1 \times 1)$-Pd-fcc(111) surface unit cell. This has been found to give sufficiently converged energies (see below). Slabs were separated by about $16 \AA$ and the dipole correction has additionally been used to reduce the artificial interaction between slabs ${ }^{6}$. All presented number have been obtained using non spin-polarized calculations. We have thoroughly tested many structures for spin-polarized solutions. However, despite using strongly magnetic guesses for the initial wave function, all converged solutions were non-magnetic. This is in agreement with calculations reported for $\mathrm{TiO}_{\mathrm{x}}$ overlayers ${ }^{7,8}$. To avoid convergence issues with surface energies, they were calculated using the 'linear-fit' method, e.g. the bulk reference energy was obtained by linear regression of the total slab-energies with respect to the number of layers. The free energy of solids and surfaces is approximated by their electronic energies. Free energies of gas phase molecules were obtained using the usual corrections from statistical thermodynamics for translation, (harmonic) oscillation and (rigid) rotation. 


\section{Estimate of experimental condition}

\section{Double layer:}

The cell was purged with pure $\mathrm{N}_{2}$ (purity $99.9995 \%$ ) and pumped to 0.1 Torr twice before it was filled with 760 Torr $5 \% \mathrm{H}_{2} / \mathrm{Ar}$ (purity 99.9995\%). Assuming air at saturated water vapor, $\sim 17$ Torr at $20{ }^{\circ} \mathrm{C}$, can go into the cell during assembling and dissembling, the calculated water vapor concentration upon pump/purging would be $0.3 \times 10^{-6}$ bar.

On the other hand, considering the impurity of the forming gas, the residual $\mathrm{H}_{2} \mathrm{O}$ and $\mathrm{O}_{2}$ will result in a concentration of $0.6 \mathrm{ppm} \mathrm{H}_{2} \mathrm{O}$, corresponding to $0.6 \times 10^{-6}$ bar. Therefore, we assume that the initial water pressure is $10^{-6}$ bar or lower and will use $10^{-6}$ bar here as the upper limit.

The experimental equilibrium constant $\left(\mathrm{K}\right.$ in $\left.\operatorname{bar}^{-0.5}\right)$ for the reaction

$$
0.5 \mathrm{O}_{2}+\mathrm{H}_{2} \rightarrow \mathrm{H}_{2} \mathrm{O}
$$

is at $T=700 \mathrm{~K} \log _{10}(\mathrm{~K})=15.582$ and $\log _{10}(\mathrm{~K})=13.287$ at $T=800 \mathrm{~K}$. With

$$
\mathrm{K}=\mathrm{p}\left(\mathrm{H}_{2} \mathrm{O}\right) /\left(\mathrm{p}\left(\mathrm{H}_{2}\right) * \mathrm{p}\left(\mathrm{O}_{2}\right)^{0.5}\right)
$$

It follows that $\mathrm{p}\left(\mathrm{O}_{2}\right) \sim 10^{-41}$ bar at $T=700 \mathrm{~K}$ and $\mathrm{p}\left(\mathrm{O}_{2}\right) \sim 10^{-36}$ bar at $T=800 \mathrm{~K}$.

Using the experimental reaction energy and employing the usual corrections from statistical thermodynamics for translation, (harmonic) oscillation, (rigid) rotation, we obtain for $T=773.15 \mathrm{~K}, \mathrm{p}\left(\mathrm{H}_{2}\right)=0.05$ bar, $\mathrm{p}\left(\mathrm{H}_{2} \mathrm{O}\right)=10^{-6}$ bar, $\mu_{\mathrm{O}}=-3.7 \mathrm{eV}$. The experimental condition would be located at somewhere smaller than $-3.7 \mathrm{eV}$.

\section{Single layer:}

The cell was filled with a mixture 15 Torr $\mathrm{O}_{2}$ and 745 Torr $5 \% \mathrm{H}_{2} / \mathrm{Ar}$. If equilibrium is reached, $\mathrm{p}\left(\mathrm{H}_{2}\right)=0.01$ bar and $\mathrm{p}\left(\mathrm{H}_{2} \mathrm{O}\right)=0.04$ bar, using the same equation shown in the double layer formation condition, we obtain $\mu_{\mathrm{O}} \sim-2.8 \mathrm{eV}$.

\section{No layer}

The cell was filled with a mixture of 43 Torr $\mathrm{O}_{2}$ and 720 Torr $5 \% \mathrm{H}_{2} /$ Ar. If equilibrium is reached, $\mathrm{p}\left(\mathrm{O}_{2}\right)=0.032$ bar and $\mathrm{p}\left(\mathrm{H}_{2} \mathrm{O}\right)=0.048$ bar, and the corresponding chemical potential would be $\mu_{\mathrm{O}} \sim-0.9 \mathrm{eV}$. 


\section{Figure S1}
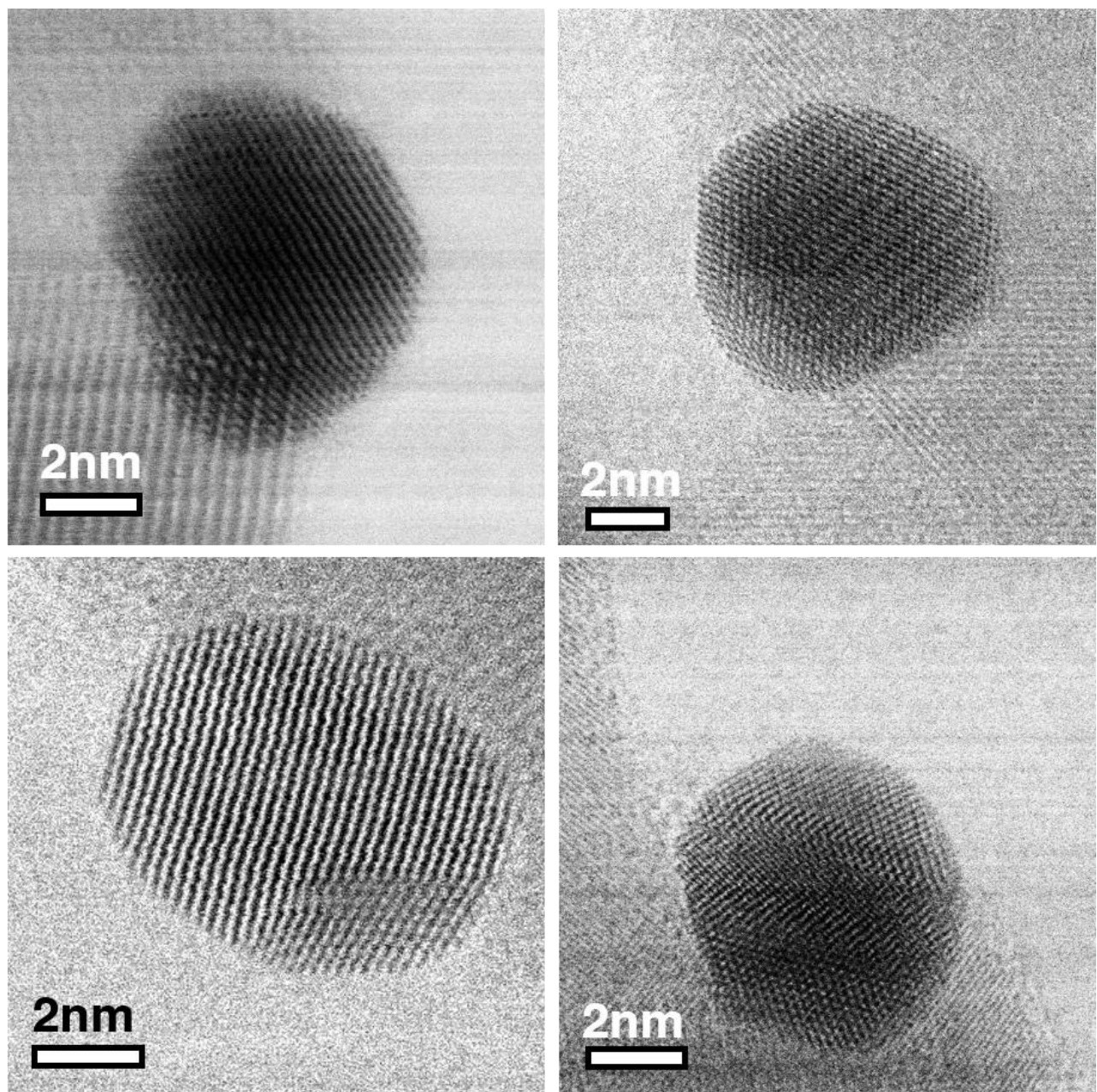

Ex situ BF STEM images showing that the surfaces of the Pd particles are initially (i.e., before conducting the in-situ experiments) clean at room temperature. 


\section{Figure S2}
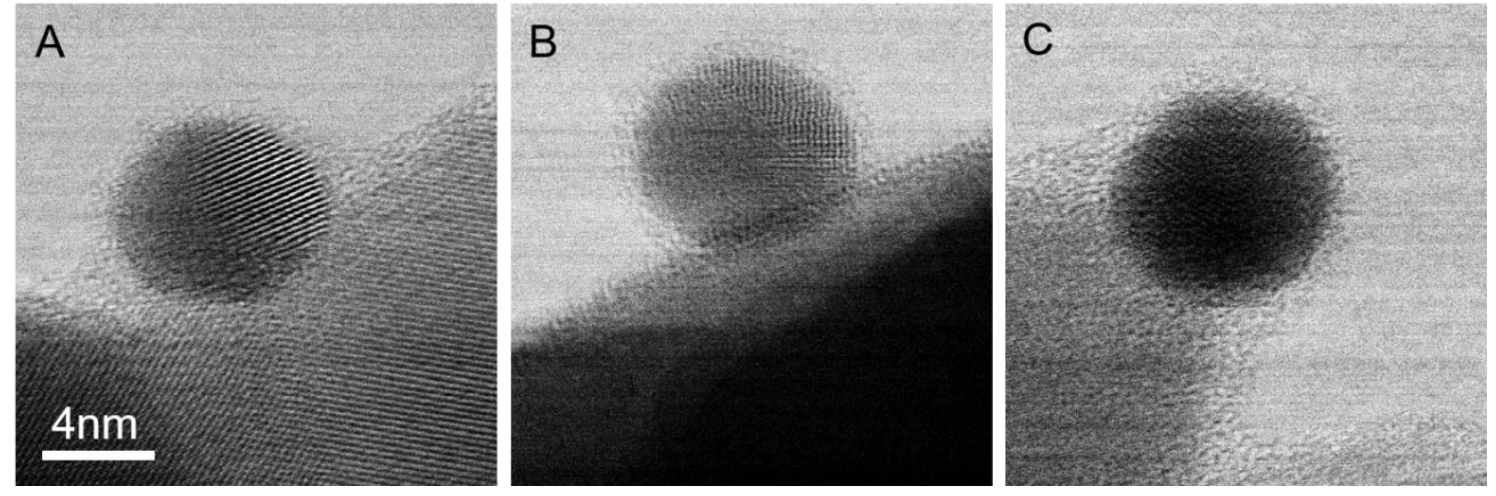

ABF STEM images taken in situ showing that most of the $\mathrm{Pd}$ particles in $\mathrm{Pd} / \mathrm{TiO}_{2}$ are covered by a thin amorphous layer at $300{ }^{\circ} \mathrm{C}$ under $\mathrm{H}_{2}(5$ vol. \%)/Ar at 1 atm. 


\section{Figure S3}
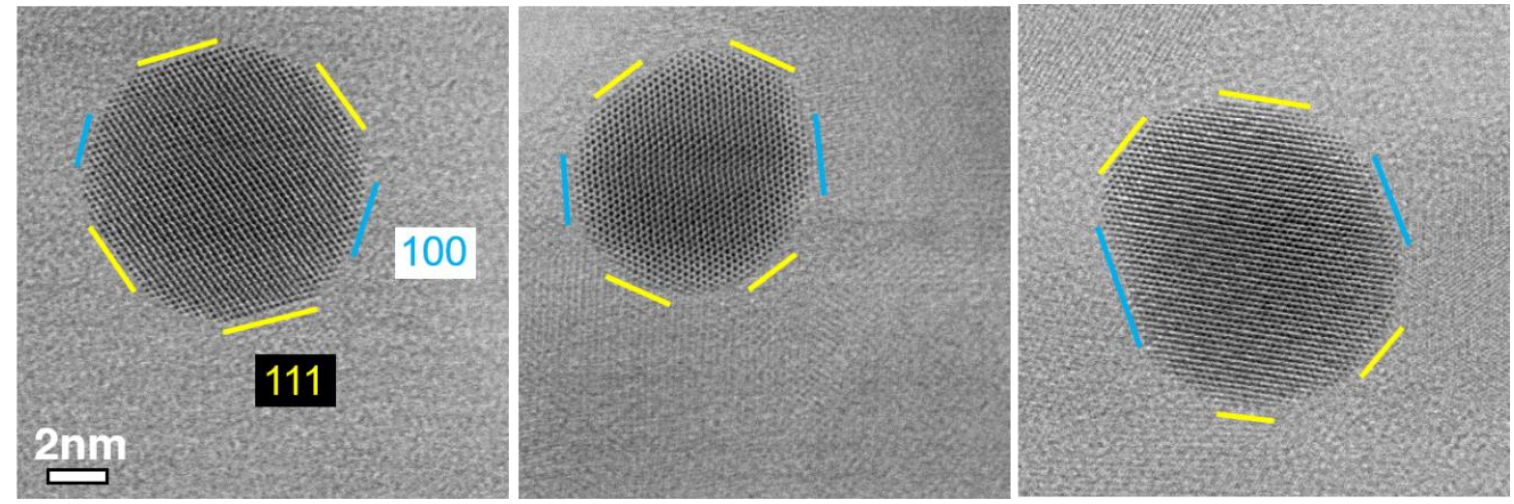

ABF STEM images showing that no change occurred when $\mathrm{Pd} / \mathrm{Al}_{2} \mathrm{O}_{3}$ was heated under $\mathrm{H}_{2}$ (5 vol. \%)/Ar at $1 \mathrm{~atm}$ total pressure at $500{ }^{\circ} \mathrm{C}$. The shape of the $\mathrm{Pd}$ nanoparticle is a truncated octahedron with smooth truncation between the two major facets, (111) and (100). 


\section{Figure S4-S6}

\section{Beam effect considerations}

We are aware that beam effects could possibly create artifacts. All the images were taken with a significantly reduced probe current, $\sim 7 \mathrm{pA}$, while the probe current for normal STEM imaging is between 50-100 pA ${ }^{9,10}$. To minimize beam effect, Chi et al. used $20 \mathrm{pA}$ probe current to study in-situ surface faceting of metal particles of similar size ${ }^{11}$. Our probe size is estimated to be about $0.8 \AA$, which is typical for state-of-the-art aberration corrected STEM (1.3 $\AA$ after the membrane), before crossing the membrane of the cell. Our current density is $4 \mathrm{pA} / \AA^{2}$, about 1 to 2 orders of magnitude lower than typical values ${ }^{12}$. Our electron dose could go up to $10^{4} \mathrm{e} / \AA^{2}$ to acquire the highest quality image, but we immediately reduced it to less than $100 \mathrm{e} / \AA^{2}$ after image acquisition. One direct way to identify the occurrence of electron beam damage is to record images of the same area before and after irradiation and compare the contrast under the same imaging conditions. No change was found when the samples were illuminated with the same conditions for prolonged time, as shown in the figures below.

At a relatively higher oxygen potential $\left(\mathrm{H}_{2}(4.7 \mathrm{vol} . \%) / \mathrm{O}_{2}(5.7 \mathrm{vol} . \%) / \mathrm{Ar}\right.$, $\mu_{\mathrm{O}} \sim-0.9 \mathrm{eV}$ ), the surfaces of $\mathrm{Pd}$ particles stayed clean at $500{ }^{\circ} \mathrm{C}$ during $20 \mathrm{~min}$ observation, as shown in Figure $\mathrm{S} 4$.

At lower oxygen potential $\left(\mathrm{H}_{2}(5 \mathrm{vol} . \%) / \mathrm{Ar}, \mu_{\mathrm{O}}<-3.7 \mathrm{eV}\right)$, an amorphous layer starts to migrate onto the particles at temperatures around $250{ }^{\circ} \mathrm{C}$. During $15 \mathrm{~min}$ observation at $250{ }^{\circ} \mathrm{C}$ under $\mathrm{H}_{2}(5$ vol. \%)/Ar at 1 atm, no change was observed, as shown in Figure S5. Finally, when the temperature was raised to $500{ }^{\circ} \mathrm{C}$ under the same gas atmosphere $\left(\mathrm{H}_{2}(5\right.$ vol. \%)/Ar at $1 \mathrm{~atm})$, two crystalline layers were instantaneously formed, and they were observed to be very stable under the beam illumination for $90 \mathrm{~min}$, as shown in Figure S6. Furthermore, as shown in Figures S3 and S10, no over layer formed when the support material was changed to $\mathrm{Al}_{2} \mathrm{O}_{3}$, or the metal was changed to $\mathrm{Au}$, suggesting the formation of the over layer is material dependent but not electron beam dependent.

Thus, we believe that the electron beam didn't play a significant role in any of the phenomena reported in this paper. 

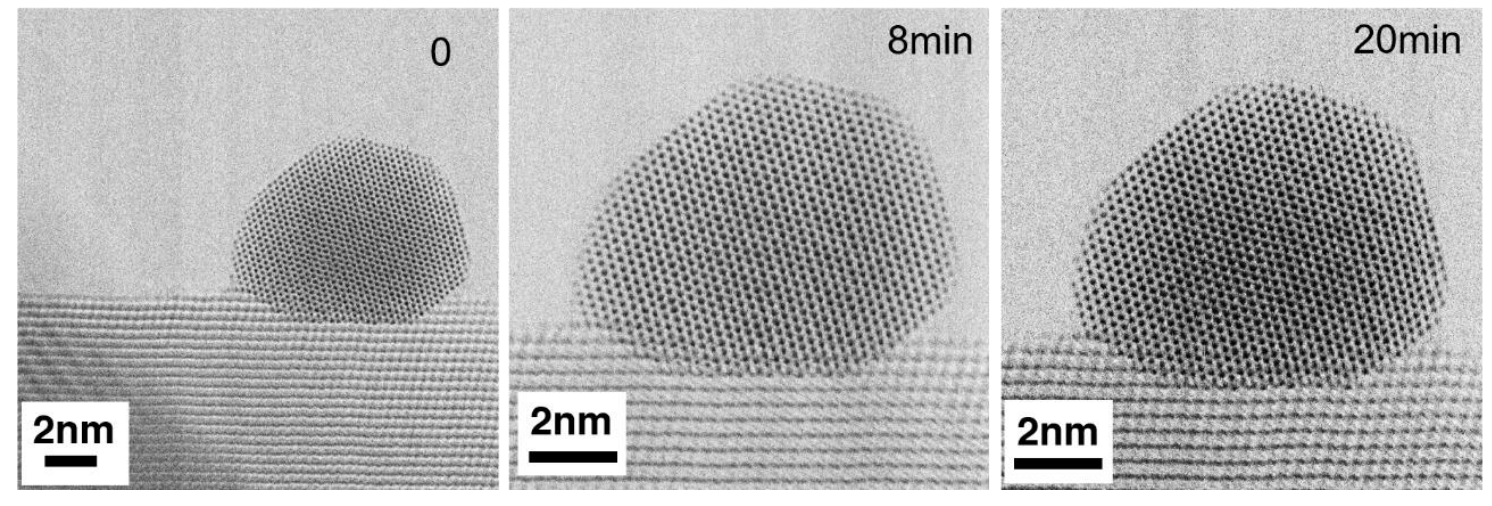

Figure $\mathrm{S} 4 \mathrm{ABF}$ images showing that no amorphous layer migrate onto the particle under $\mathrm{H}_{2}\left(4.7\right.$ vol. \%)/ $\mathrm{O}_{2}\left(5.7\right.$ vol. \%)/Ar at $500{ }^{\circ} \mathrm{C}$ during 20 mins electron beam illumination.
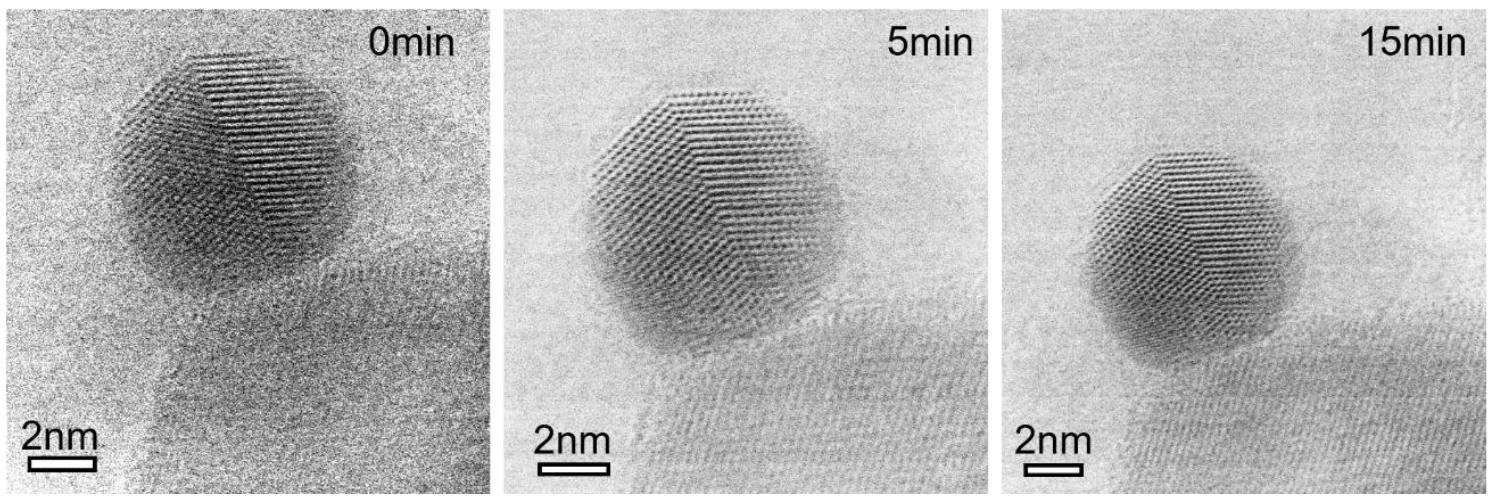

Figure S5 ABF images showing that an amorphous layer start to form on the surface of the particle at $250{ }^{\circ} \mathrm{C}$ under $\mathrm{H}_{2}(5 \mathrm{vol} . \%) / \mathrm{Ar}$ at $1 \mathrm{~atm}$ and no changes have been observed in the images taken at varied time. 

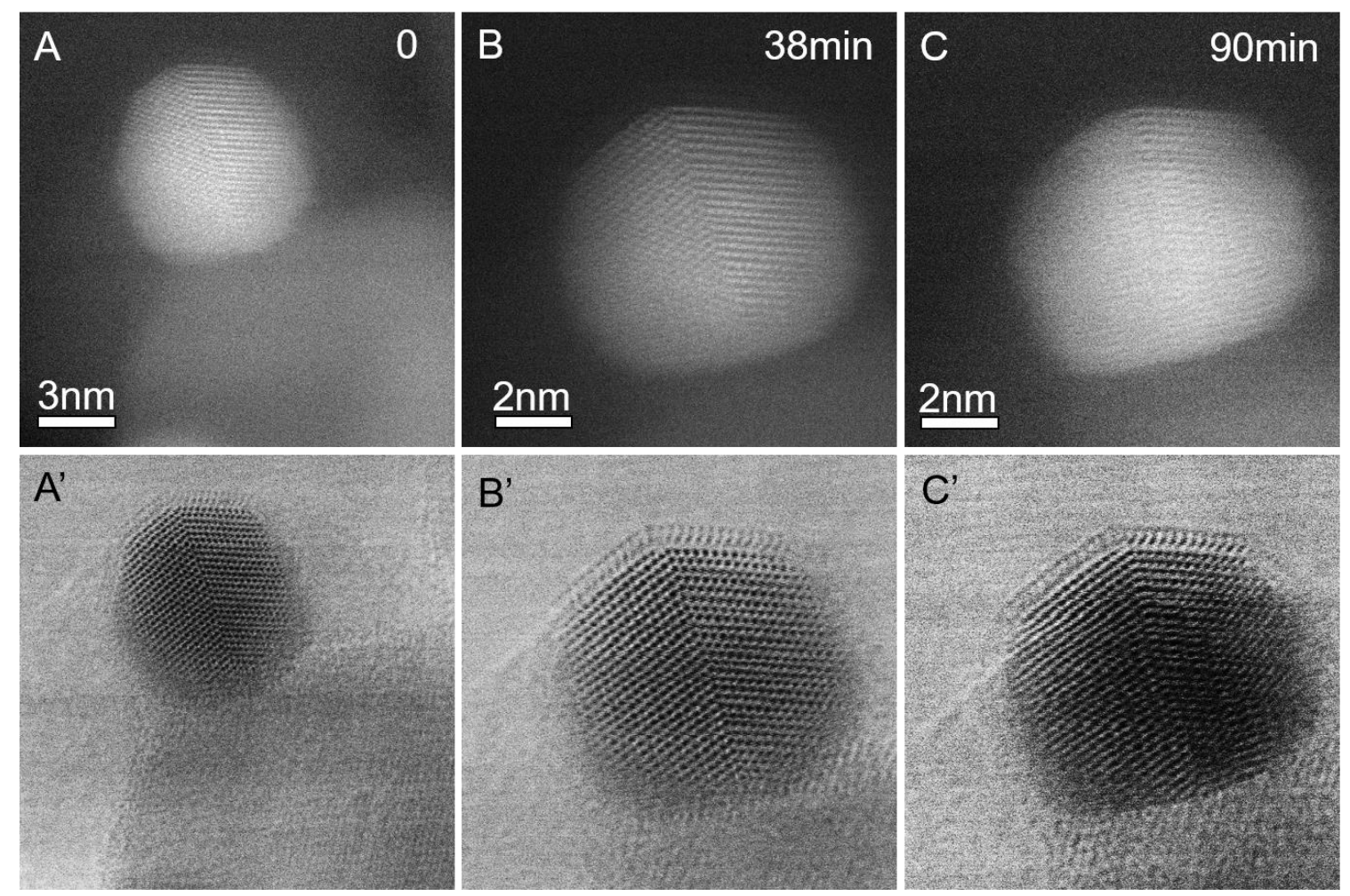

Figure S6 Pairs of HAADF and ABF images showing that no structural damage can be discerned in the images taken at varied time up to 90 mins of illumination at $500{ }^{\circ} \mathrm{C}$ under $\mathrm{H}_{2}(5$ vol. \%)/Ar at 1 atm. 


\section{Figure S7}
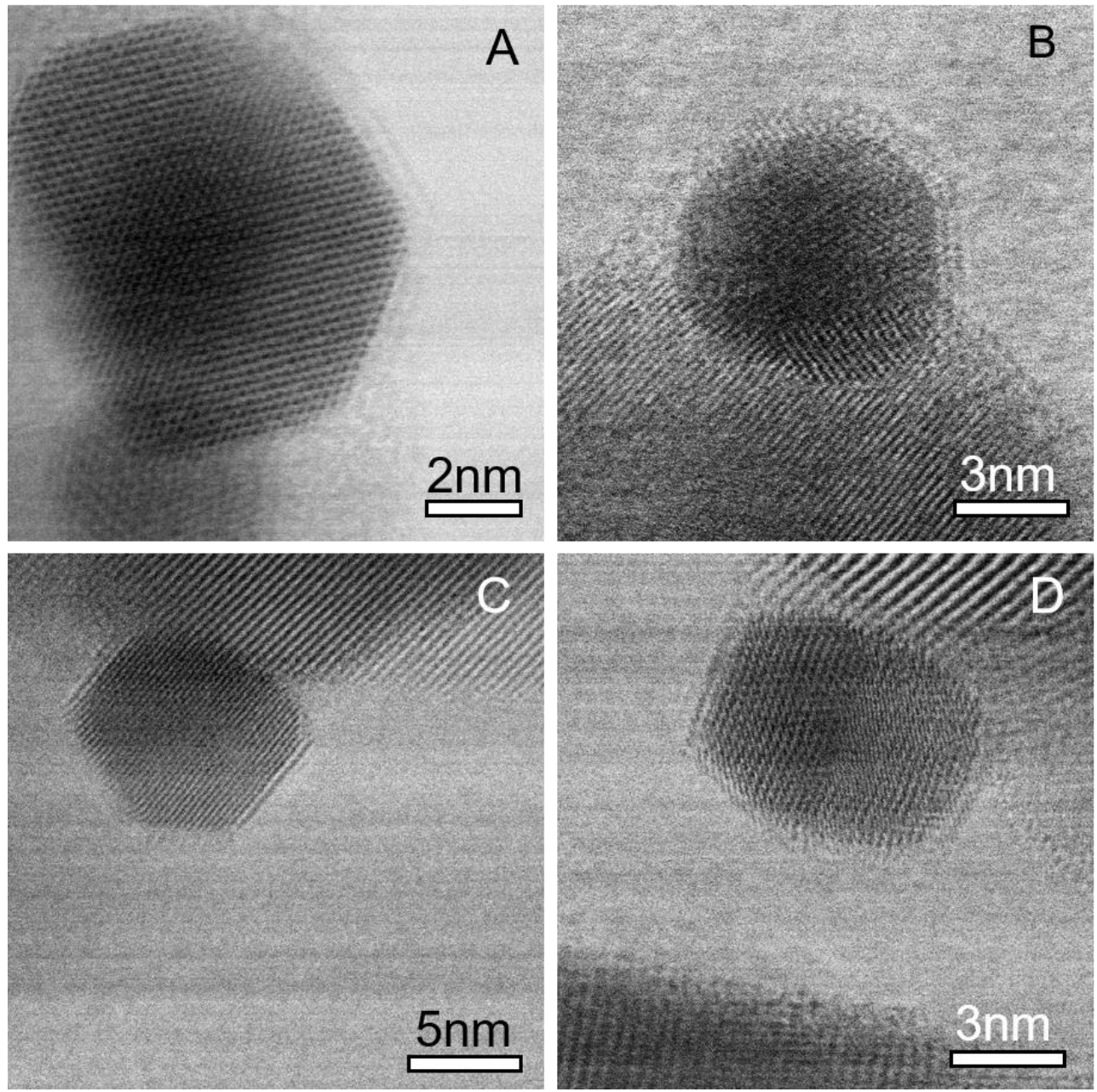

$\mathrm{ABF}$ images showing more examples of double TiOx layer formed under $\mathrm{H}_{2}(5$ vol. \% $) / \mathrm{Ar}$ at $1 \mathrm{~atm}$ at $500{ }^{\circ} \mathrm{C}(\mathrm{A}, \mathrm{B})$ and single layer formed under $\mathrm{H}_{2}(4.9 \mathrm{vol} . \%) / \mathrm{O}_{2}(2 \mathrm{vol} . \%) / \mathrm{Ar}$ at 1 atm at $500{ }^{\circ} \mathrm{C}(\mathrm{C}, \mathrm{D})$. 


\section{Figure S8}
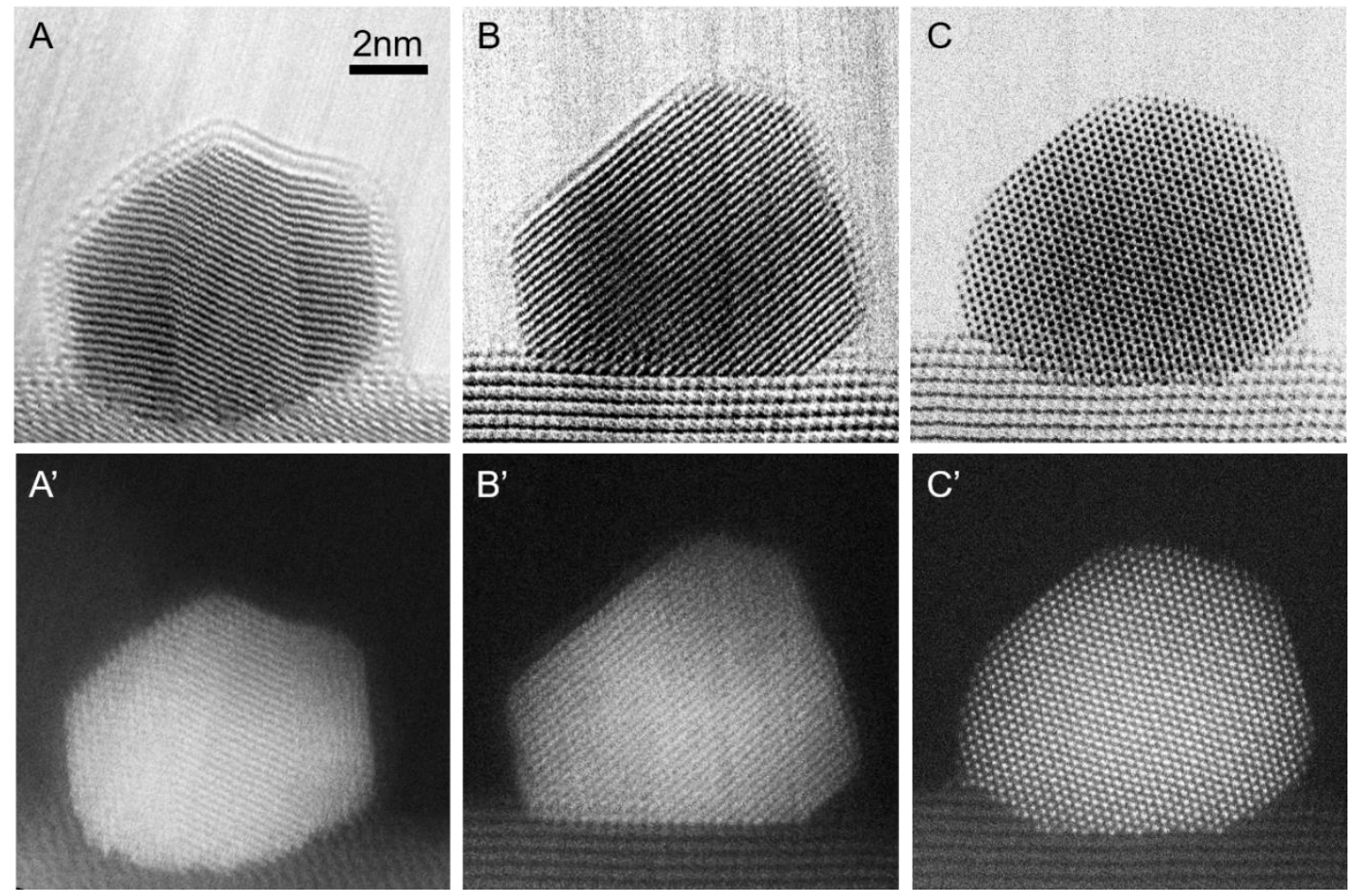

Original ABF images (A-C) and HAADF image (A'-C') of the false color images shown in Figure 2B-D. 


\section{Figure S9}
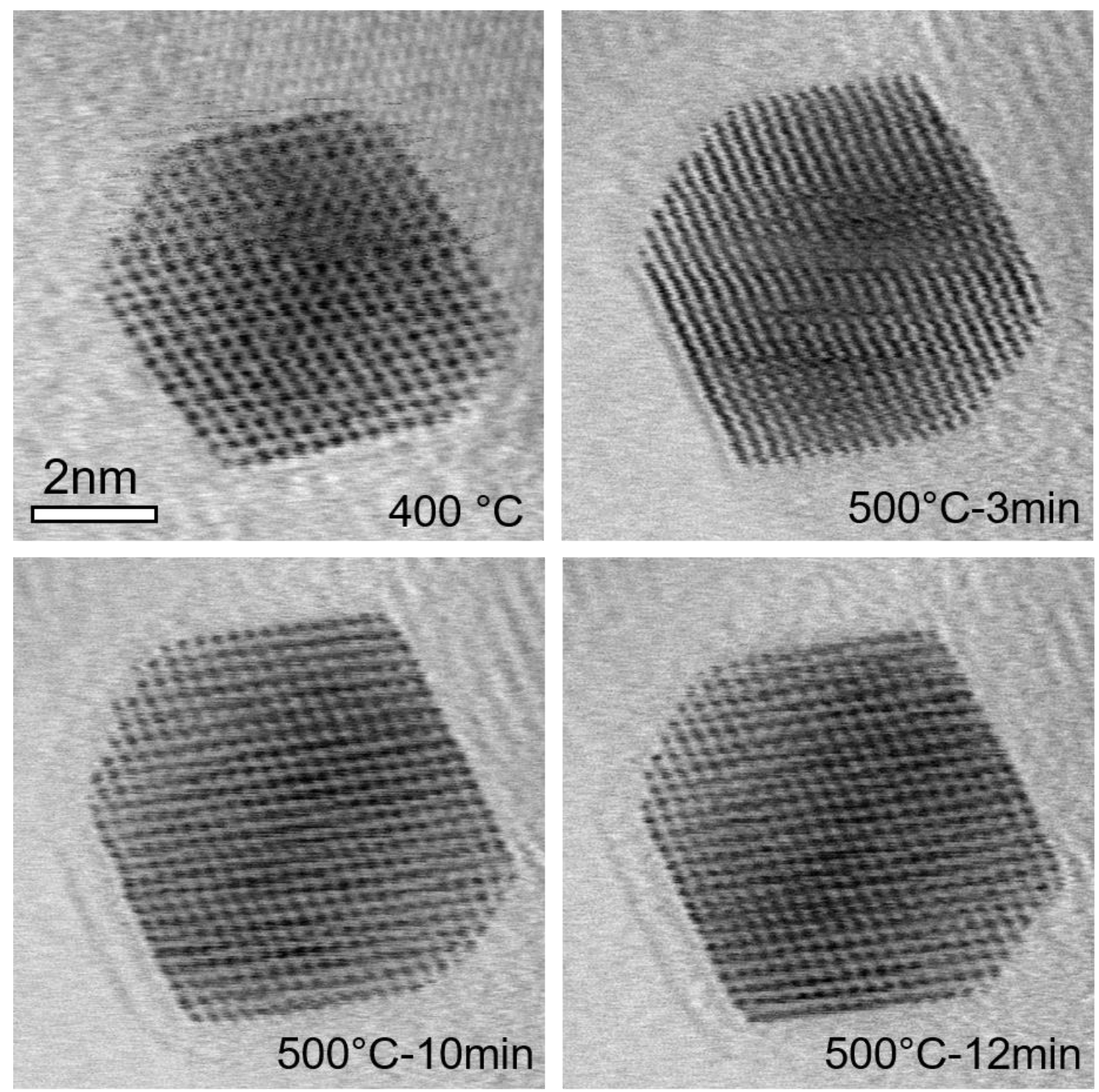

$\mathrm{ABF}$ images showing the formation of $\mathrm{TiO}_{\mathrm{x}}$ double layer on $\mathrm{Pt}$ particles in $\mathrm{Pt} / \mathrm{TiO}_{2}$ under $\mathrm{H}_{2}(5$ vol. \%)/Ar at $1 \mathrm{~atm}$. 


\section{Figure S10}
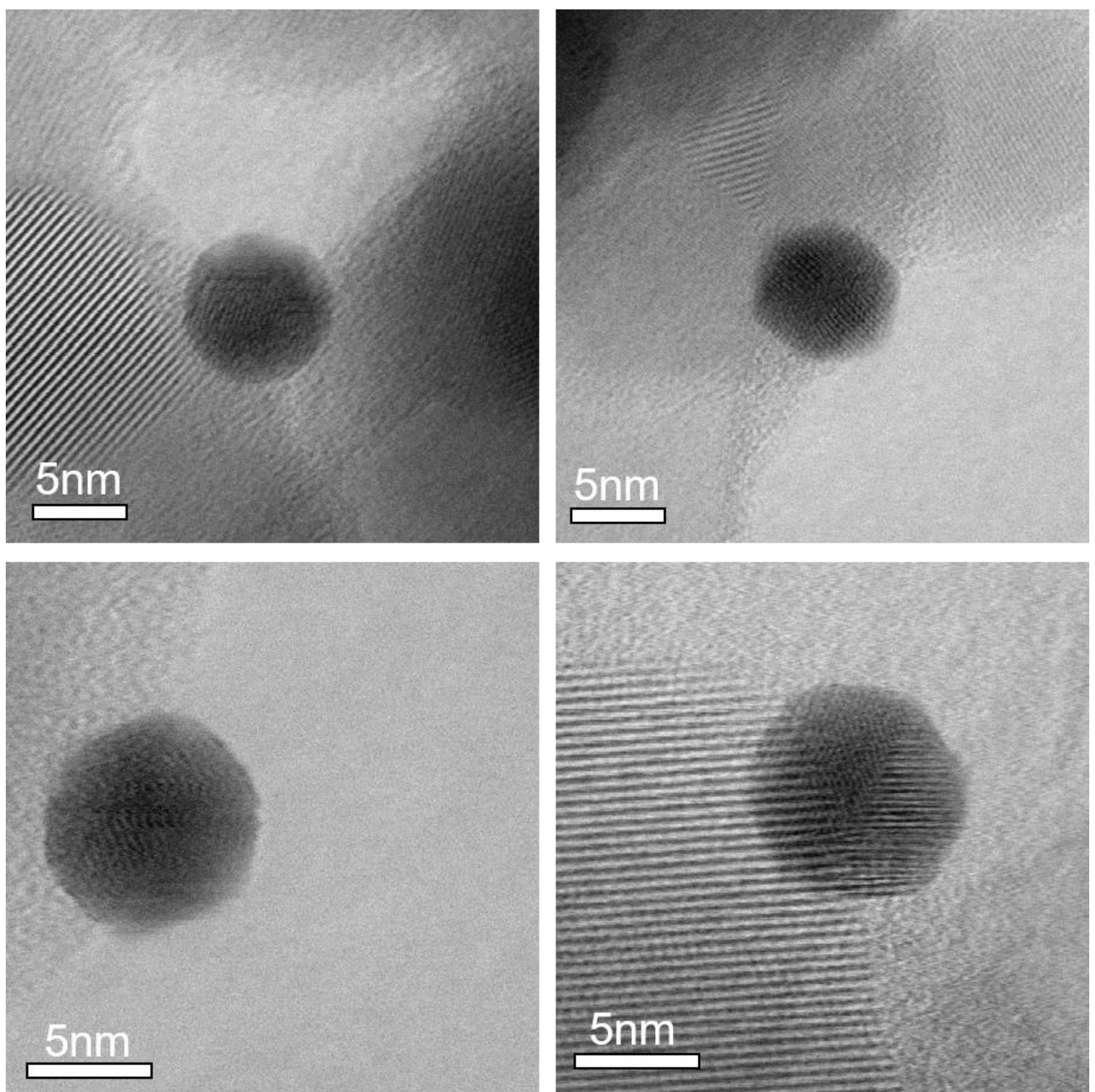

$\mathrm{ABF}$ images showing that the surface of Au particles in $\mathrm{Au} / \mathrm{TiO}_{2}$ are clean after $1 \mathrm{~h}$ heating under $\mathrm{H}_{2}(5 \mathrm{vol} . \%) / \mathrm{Ar}$ at $1 \mathrm{~atm}$ at $500{ }^{\circ} \mathrm{C}$. 


\section{DFT calculation result of $\mathrm{Pt}$ and $\mathrm{Au}$}

We have computed the thermodynamic stability of k-phase single and double layers of $\mathrm{TiO}_{\mathrm{x}}$ in the $(1 \times 1) /(2 \times 2)$ super cell on $\mathrm{Pt}$ and $\mathrm{Au}$, as well as Pd. Generally, both overlayers are stable on Pd and Pt and unstable on Au.

Table S1 Comparison of the stability of the k-phase single and double layers of $\mathrm{TiO}_{\mathrm{x}}$ on the (111) facets of different metals on at $\mu_{\mathrm{O}}=-3.7 \mathrm{eV}$. Free energies of formation are given in $\mathrm{eV}$.

\begin{tabular}{|c|c|c|}
\hline & single & double \\
\hline $\mathrm{Au}$ & 0.04 & 0.18 \\
\hline $\mathrm{Pd}$ & -0.23 & -0.19 \\
\hline $\mathrm{Pt}$ & -0.32 & -0.40 \\
\hline
\end{tabular}

\section{Figure S11}

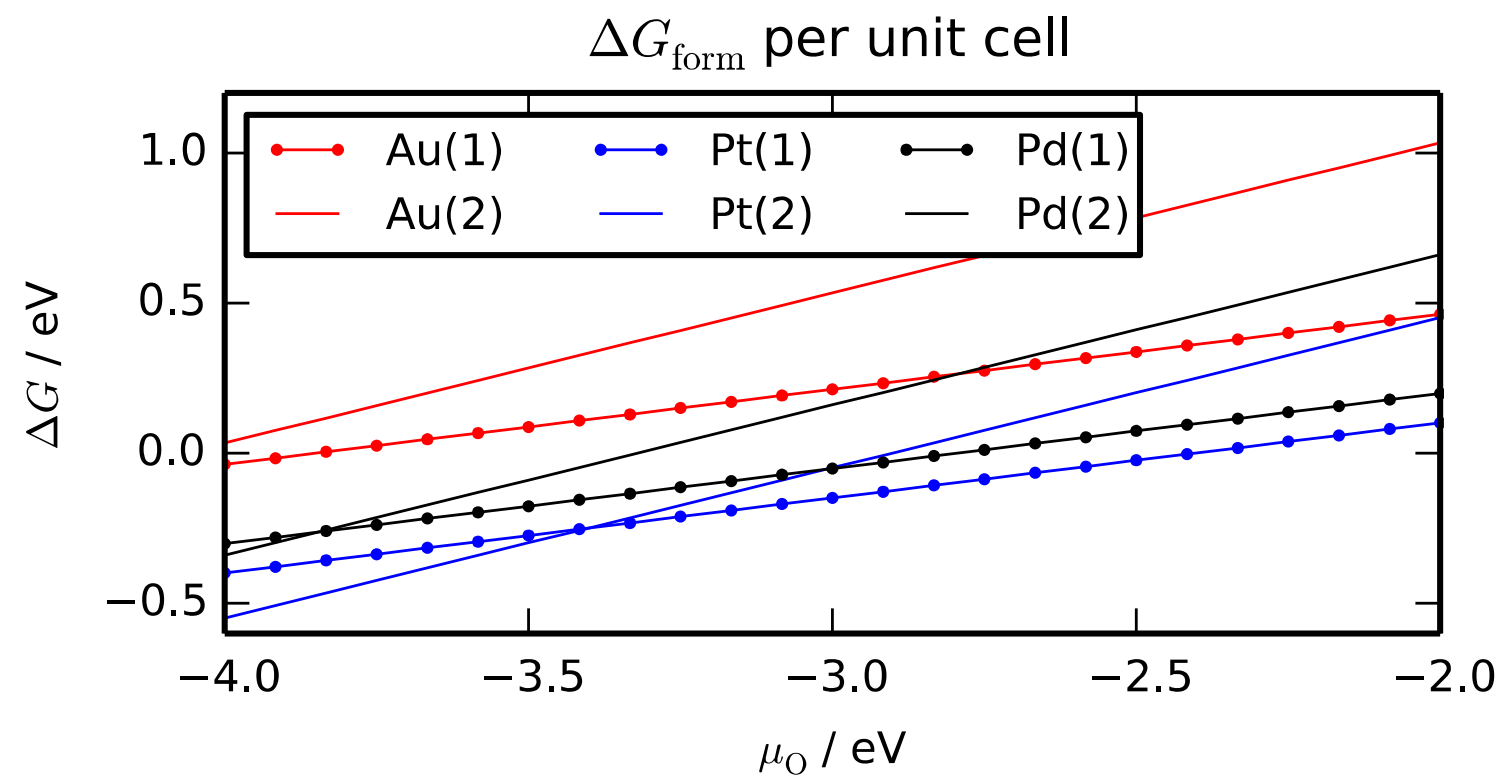

Stability of k-phase single and double-layer $\mathrm{TiO}_{\mathrm{x}}$ structures supported on (111) $\mathrm{Au}, \mathrm{Pd}$ and Pt. The number of layers is given in parentheses. 


\section{Figure S12}

Wulff construction

$$
\frac{\gamma_{100}}{\gamma_{111}}=\frac{h_{100}}{h_{111}}=\sqrt{3} \frac{N_{T}}{N_{p}}
$$

$\gamma$ is the surface energy of specific plane and $\mathrm{h}$ is the distance from the center of the supported NP. The diameter of the NP is given by $\left(a_{0} / \sqrt{2}\right) \cdot N_{P}$. So Np is the number of atomic rows along diameter and $\mathrm{N}_{\mathrm{T}}$ is the number of atomic layers from the top to the center as shown below. The tilting of the particle doesn't affect the counting of $N_{P}$ and $N_{T}$.

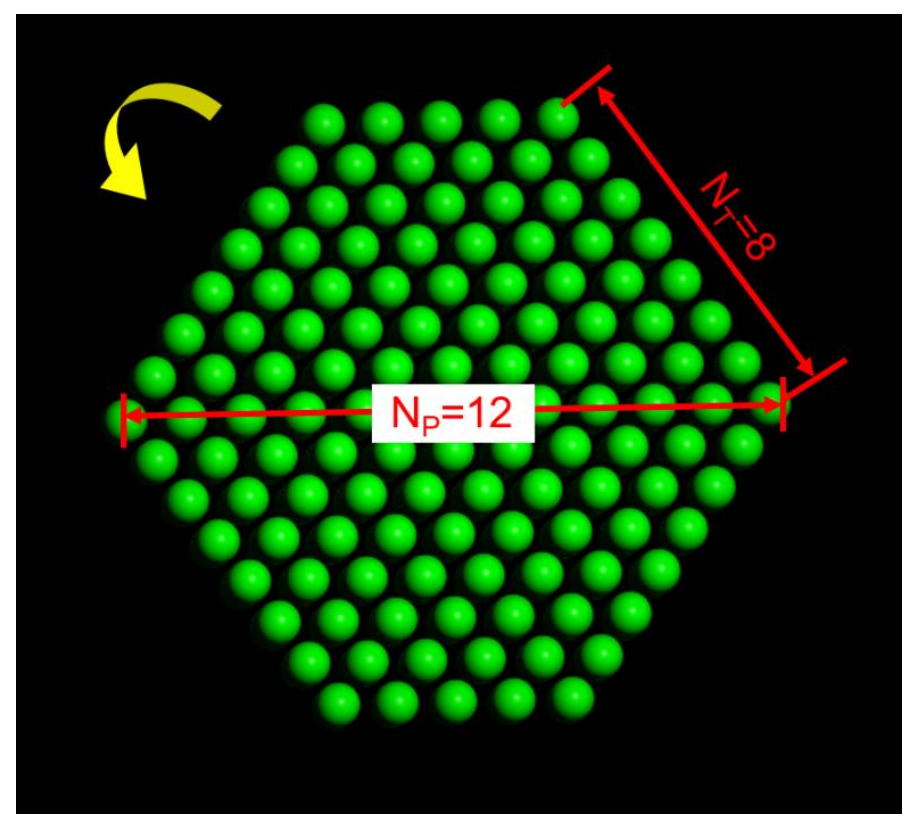

Schematic showing $\mathrm{N}_{\mathrm{P}}$ and $\mathrm{N}_{\mathrm{T}}$ 


\section{Figure S13}
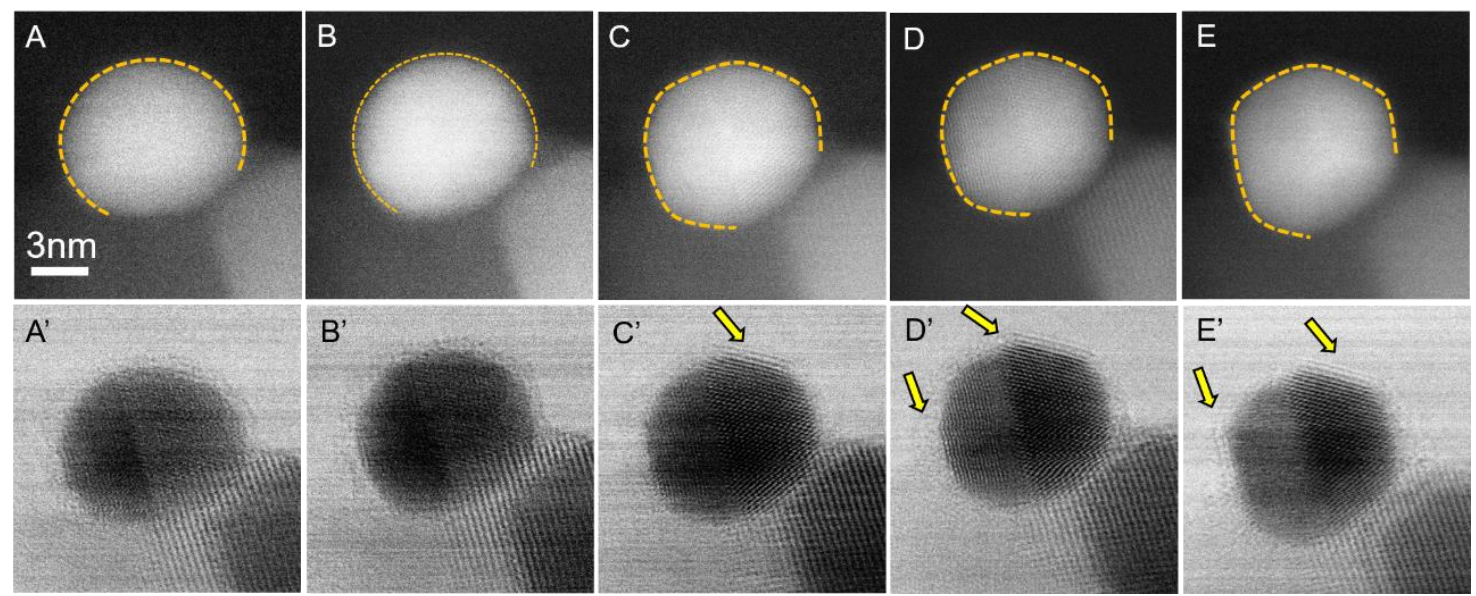

Dynamic process showing the disorder to order transition accompanied by the faceting of the particle under 760 Torr $5 \% \mathrm{H}_{2} / \mathrm{N}_{2}$ (A) $300{ }^{\circ} \mathrm{C}$ (B) $400{ }^{\circ} \mathrm{C} 2 \min$ (C) $400{ }^{\circ} \mathrm{C} 15 \min$ (D) $400{ }^{\circ} \mathrm{C} 47 \min (\mathrm{E}) 500{ }^{\circ} \mathrm{C}$. 


\section{Figure S14}
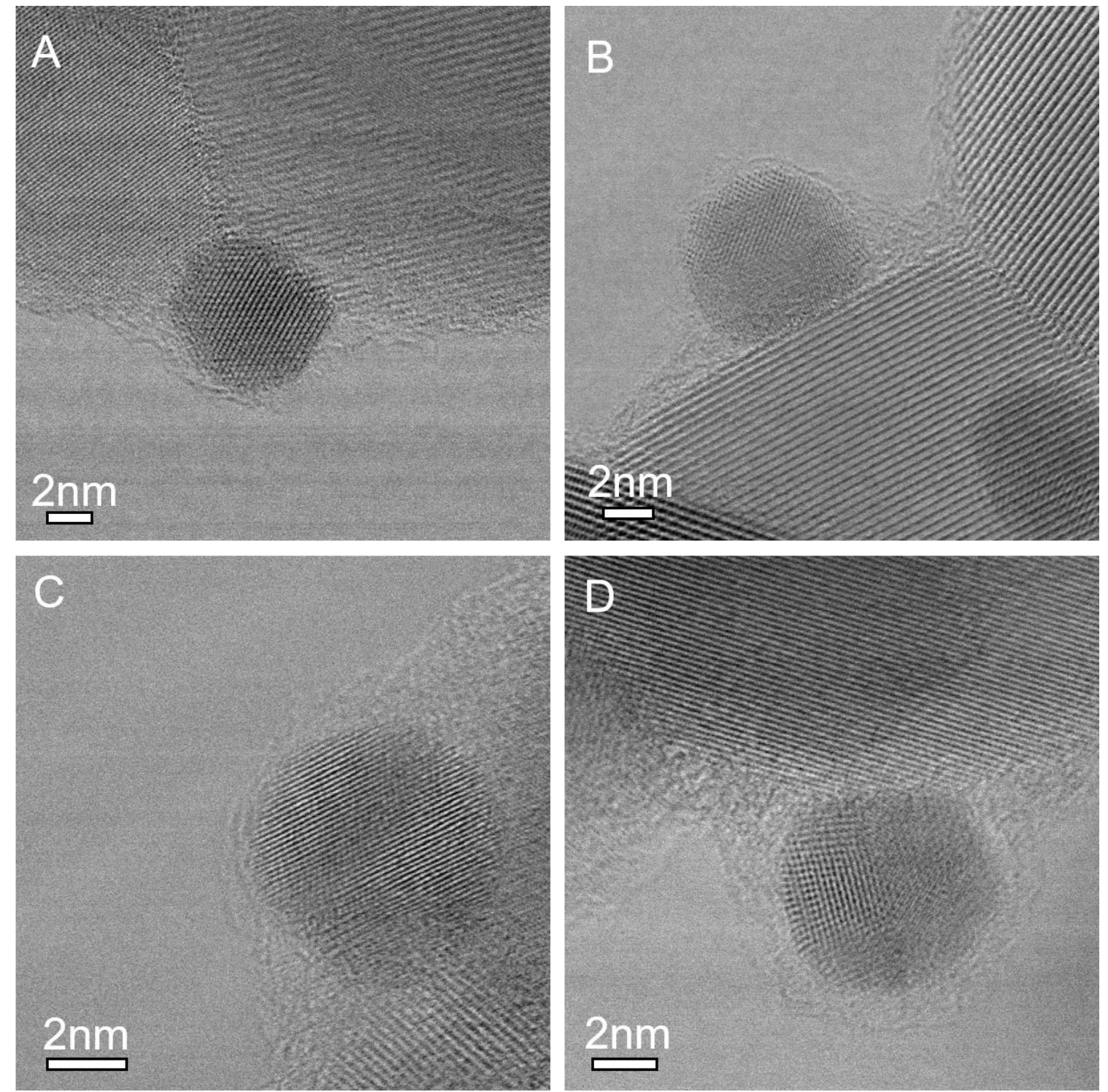

$\mathrm{ABF}$ images showing that after ex situ reduction conducted in a tube furnace for $1 \mathrm{hr}$ at $500{ }^{\circ} \mathrm{C}$ under $\mathrm{H}_{2}\left(5\right.$ vol. \%)/Ar, $\mathrm{Pd}$ particles in $\mathrm{Pd} / \mathrm{TiO}_{2}$ are covered by a thin amorphous layer, which is in accordance with most of the literature reports. No crystalline layer can be discerned. 


\section{More Details of the DFT calculations}

\section{Convergence Tests}

We have tested the accuracy resulting from different k-point sampling and plane wave cutoffs for mono- and double-layer of the k-phase for the smallest supercell, $1 \times 1 / 2 \times 2$. As shown in Table S2, we expect the chosen plane-wave cutoff (500 eV) to give energies that are accurate to $0.01 \mathrm{eV}$ per Ti atom. A similar accuracy is reached with a $8 \times 8 \times 1 \mathrm{k}-$ point sampling. Using a sampling of $6 \times 6 \times 1$ results in an error of about $0.03 \mathrm{eV}$, which is still acceptable.

Table S2 Formation energy (eV) of double and monolayer in a 1x1/2x 2 supercell as a function of k-point sampling and wave function plane-wave cutoff.

\begin{tabular}{|l|l|r|r|r|r|}
\hline & & \multicolumn{1}{l|}{$\begin{array}{l}\text { mono- } \\
\text { layer }\end{array}$} & \multicolumn{1}{l|}{$\begin{array}{l}\text { mono- } \\
\text { layer }\end{array}$} & double-layer & double-layer \\
\hline Cutoff & k-points & \multicolumn{1}{l|}{$\begin{array}{l}\text { Eform / } \\
\text { (Ti) }\end{array}$} & $\begin{array}{l}\text { Eform / } \\
\text { n(Ti) }\end{array}$ & \multicolumn{1}{l|}{$\begin{array}{l}\text { Eform / } \\
\text { n(Ti) }\end{array}$} & Eform / n(Ti) \\
\hline $1000 \mathrm{eV}$ & $4 \times 4 \times 1$ & 1.317 & 0.027 & 3.117 & 0.024 \\
\hline $1000 \mathrm{eV}$ & $6 \times 6 \times 1$ & 1.261 & -0.029 & 3.060 & -0.033 \\
\hline $1000 \mathrm{eV}$ & $8 \times 8 \times 1$ & 1.302 & 0.013 & 3.106 & 0.013 \\
\hline $1000 \mathrm{eV}$ & $10 \times 10 \times 1$ & 1.296 & 0.007 & 3.097 & 0.004 \\
\hline $1000 \mathrm{eV}$ & $12 \times 12 \times 1$ & 1.289 & $:=0$ & 3.093 & $:=0$ \\
\hline $400 \mathrm{eV}$ & $8 \times 8 \times 1$ & 1.288 & -0.014 & 3.076 & -0.031 \\
\hline $500 \mathrm{eV}$ & $8 \times 8 \times 1$ & 1.306 & 0.004 & 3.098 & -0.008 \\
\hline $600 \mathrm{eV}$ & $8 \times 8 \times 1$ & 1.307 & 0.005 & 3.111 & 0.004 \\
\hline $800 \mathrm{eV}$ & $8 \times 8 \times 1$ & 1.302 & 0.000 & 3.107 & 0.001 \\
\hline $1000 \mathrm{eV}$ & $8 \times 8 \times 1$ & 1.302 & $:=0$ & 3.106 & $:=0$ \\
\hline
\end{tabular}




\section{Lattice mismatch}

Before turning to minimizing the lattice mismatch, it is important to realize that it is to some extent depending on temperature and partial pressures. As $\mu_{0}$ determines the stability of an overlayer, the same overlayer in different supercells with different deficiency of oxygen per unit cell will lead to different slopes in the plot of free energy of formation versus $\mu_{\mathrm{O}}$. This is shown below for two stable supercells of the single layer k-phase structure. The super cell with higher coverage of the k-phase, $(1 \times 1) /(2 \times 2)$, is more oxygendefiant per surface area. Consequently the slope is larger and this structure is more stable at lower $\mu_{\mathrm{O}}$, while the other is more stable at $\mu_{\mathrm{O}}$. The crossover occurs in the relevant region of $\mu_{\mathrm{o}}$. Since the difference is not large, we pick the less dense unit cell, because this is the supercell in which the double layer is most stable.

Figure S15

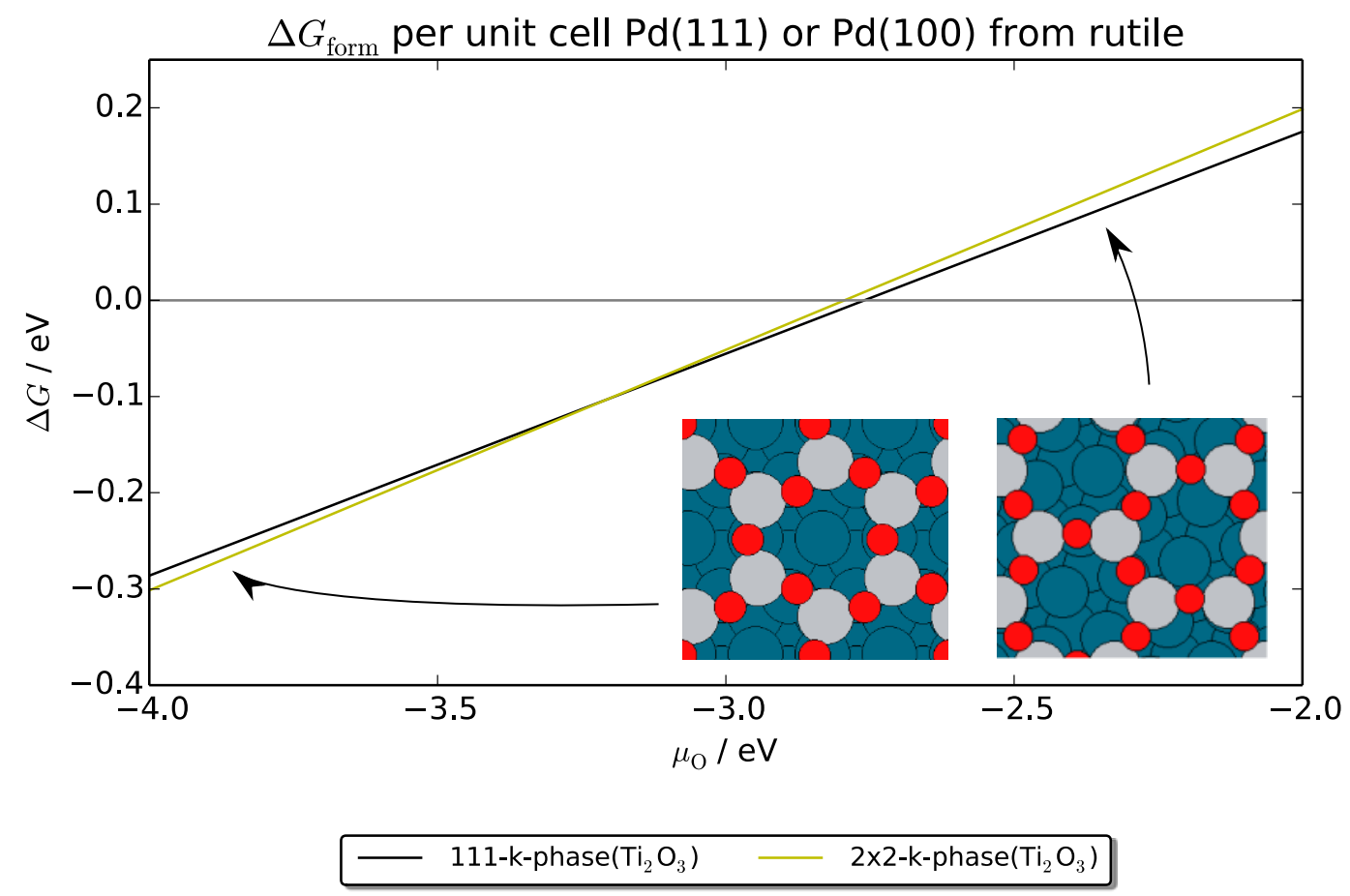

Stability of $\mathrm{Pd}(111)$-supported k-phase single layers with different coverages.

The lattice constant of the overlayer has been varied by creating various supercells (see Table S3). The obtained free energy curve as a function of lattice mismatch is depicted at $\mu_{\mathrm{O}}=-3.7 \mathrm{eV}$ in Figures $\mathrm{SX}$. This is the approximate crossover between single and double-layer. As mentioned above, two super-cells have similar stability for the single 
layer, while for the double layer it is clear, which super cell is most stable. The reason for the stability of the single layer in this small unit cell is probably that both Ti-atoms are three-fold coordinated by Pd. For all other supercells this is not the case. This unit cell is therefore likely an anomaly in the generally well-behaved potential energy curve. For the double layer, this effect is expected to be weaker as the compression acts on both layers, while the effect of interface bonding affects only one layer.

For the double layer, a continuous curve is obtained, both for single and double layer. Since the overlayer generally has different orientations with respect to the support, this means that the influence of the orientation is likely smaller. At higher lattice-constants, where the overlayer becomes unstable, two different orientations leading to the same lattice constant, $(\sqrt{ } 3 \times \sqrt{ } 3)-R 30^{\circ} /(4 \times 4)$ and $(3 \times 3) /(4 \sqrt{ } 3 \times 4 \sqrt{ } 3)-R 30^{\circ}$, give a very similar formation energy.

Table S3 Data used to determine the minimum lattice mismatch. The k-point density in one dimension is given by the number of $\mathrm{Pd}$ atoms in one direction times the number of $\mathrm{k}$-points in this direction.

\begin{tabular}{|c|c|c|c|c|c|c|}
\hline supercell & $\begin{array}{c}\text { Lengths } \\
/ \AA\end{array}$ & $\begin{array}{c}\text { k-phase- } \\
\text { layers }\end{array}$ & $\begin{array}{c}\text { k-point } \\
\text { grid }\end{array}$ & $\begin{array}{c}1 \mathrm{D}-\mathrm{k} \text {-point } \\
\text { density }\end{array}$ & $\begin{array}{c}2 \text { Pd layers } \\
\mathrm{G} / \mathrm{eV}\end{array}$ & $\begin{array}{c}4 \text { Pd layers } \\
\mathrm{G} / \mathrm{eV}\end{array}$ \\
\hline $\begin{array}{c}(\sqrt{3} \times \sqrt{ } 3)-R 30^{\circ} / \\
(\sqrt{ } 13 \times \sqrt{ } 13)-R 14^{\circ}\end{array}$ & 5.81 & double & $2 \times 2 \times 1$ & 7.2 & -0.232 & -0.241 \\
\hline & & single & $2 \times 2 \times 1$ & 7.2 & -0.211 & -0.228 \\
\hline & & double & $3 \times 3 \times 1$ & 10.8 & & -0.227 \\
\hline & & single & $3 \times 3 \times 1$ & 10.8 & & -0.217 \\
\hline & & double & $4 \times 4 \times 1$ & 14.4 & -0.228 & -0.226 \\
\hline & & single & $4 \times 4 \times 1$ & 14.4 & -0.215 & -0.216 \\
\hline & 5.64 & double & $1 \times 1 \times 1$ & 7.0 & -0.187 & \\
\hline & & single & $1 \times 1 \times 1$ & 7.0 & -0.194 & \\
\hline & double & $2 \times 2 \times 1$ & 14.0 & -0.216 & \\
\hline
\end{tabular}




\begin{tabular}{|c|c|c|c|c|c|c|}
\hline & & single & $2 \times 2 \times 1$ & 14.0 & -0.205 & \\
\hline$(1 \times 1) /(2 \times 2)$ & 5.58 & double & $6 \times 6 \times 1$ & 12.0 & -0.197 & -0.189 \\
\hline & & single & $6 \times 6 \times 1$ & 12.0 & -0.192 & -0.225 \\
\hline$(4 \times 4) /(5 \sqrt{3} \times 5 \sqrt{3})-R 30^{\circ}$ & 6.04 & double & $1 \times 1 \times 1$ & 8.7 & -0.187 & \\
\hline & & single & $1 \times 1 \times 1$ & 8.7 & -0.200 & \\
\hline$(\sqrt{3} \times \sqrt{3})-R 30^{\circ} /(4 \times 4)$ & 6.45 & double & $2 \times 2 \times 1$ & 8.0 & 0.094 & \\
\hline & & single & $2 \times 2 \times 1$ & 8.0 & -0.028 & \\
\hline$(3 \times 3) /(4 \sqrt{3} \times 4 \sqrt{3})-R 30^{\circ}$ & 6.45 & single & $1 \times 1 \times 1$ & 6.9 & -0.053 & \\
\hline
\end{tabular}

Figure S16

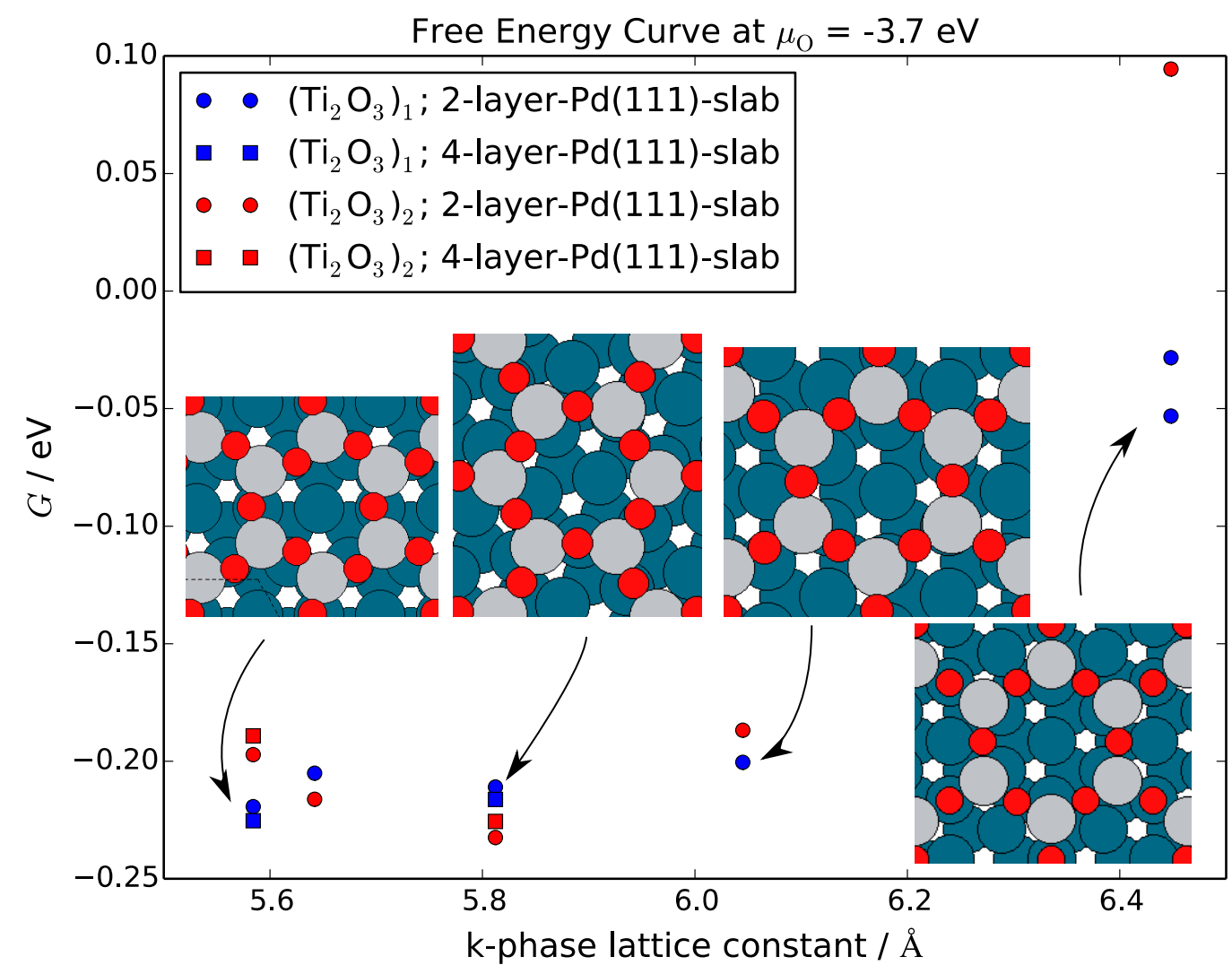

Figure SX Formation free energies per Pd-surface atom plotted agains the k-phase lattice constant. Insets shows a top view of k-phase single layer structures in various lattice constants. 


\section{Overview Pd(111) supported structures}

As described in the main text, the most stable obtained structures are the single and double layer of the k-phase. Other likely alternatives, that would also be in agreement with the experimental cross section (see below), are rocksalt(111)-derived structures. Various of the more complex reported $\mathrm{TiO}_{\mathrm{x}}$ structures are derived from a layer of closed-packed $\mathrm{Ti}$ atoms with threefold coordinated oxygen atoms in the fcc-sites. We have modeled the nondefected TiO-overlayer in a $(\sqrt{3} \times \sqrt{3})-R 30^{\circ}-\mathrm{TiO} /(2 \times 2)-\mathrm{Pd}(111)$ cell. At relatively high $\mu_{\mathrm{O}}$, the TiO-layer is found to be less stable than the $\mathrm{Ti}_{2} \mathrm{O}_{3}$ mono-layer, while its stability is competitive with the double layer of $\mathrm{Ti}_{2} \mathrm{O}_{3}$ at lower $\mu_{\mathrm{o}}$. Within the accuracy of our calculations this does certainly not rule out the existence of the double layer of $\mathrm{Ti}_{2} \mathrm{O}_{3}$, but the high density and high oxygen deficiency of the TiO-monolayer will certainly make it the most stable structure at sufficiently low $\mu_{\mathrm{O}}$.

Figure S17

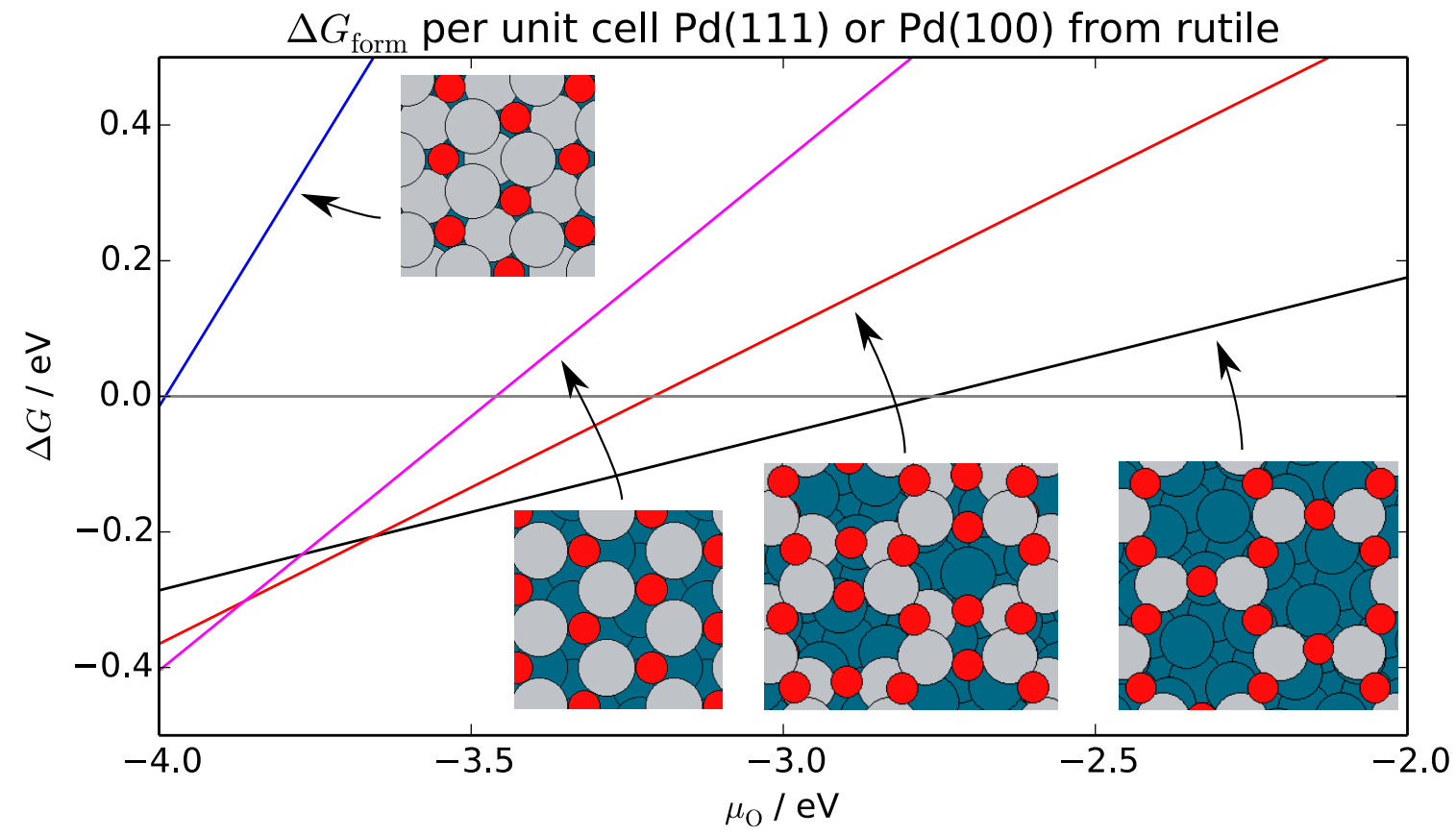

$\longrightarrow \begin{array}{l}\text { 111-k-phase }\left(\mathrm{Ti}_{2} \mathrm{O}_{3}\right) \\ \text { 111-k-phase }\left(\mathrm{Ti}_{2} \mathrm{O}_{3}\right)_{2}\end{array} \quad$ 111-rocks.(TiO) $\quad$ 111-rocks.(TiO) $)_{2}$

Stability of Pd(111)-supported structures. Structural representations are shown as insets. 


\section{Orientation and comparison to experimental cross-section}

All experimental images show rows of atoms along the view axis. It is therefore likely that this true for all three symmetry-equivalent axis of the support, although images for each particle were only taken along one axis. This means that each layer of the overlayer should have a hexagonal symmetry. The entire overlayer does not necessarily have a hexagonal symmetry, since the rotational symmetry axis can be centered at different positions, as is the case for the double layer.

Being restricted to periodic boundary conditions, various lattice mismatches can only be explored by also introducing different orientations of overlayer with respect to support, as done above. The orientation of the overlayer seems to be less important energetically, although we cannot check that explicitly in most cases. In terms of the actual orientation, it is highly likely that the support and overlayer are aligned along a symmetric axes in the most stable system, although the energetic stabilization may be small per unit cell.

There are two highly symmetric orientations, one would be to align the lattice vectors of the minimal unit cells. The other one would be to rotate either overlayer or support by $30^{\circ}$. Technically this can be realized by generating a $(\sqrt{ } 3 \times \sqrt{3})-R 30^{\circ}$ unit cell of either support or overlayer and aligning it with the corresponding other minimal unit cell. The first orientation is in disagreement with the experimentally observed cross section that shows rows of atoms along the view axis, the second is in agreement.

We illustrate this for the supercell $(2 \sqrt{3} \times 2 \sqrt{ } 3)-R 30^{\circ} /(7 \times 7)$, which is not the most stable unit cell, probably because the overlayers are stretched too much. 
Figure S18

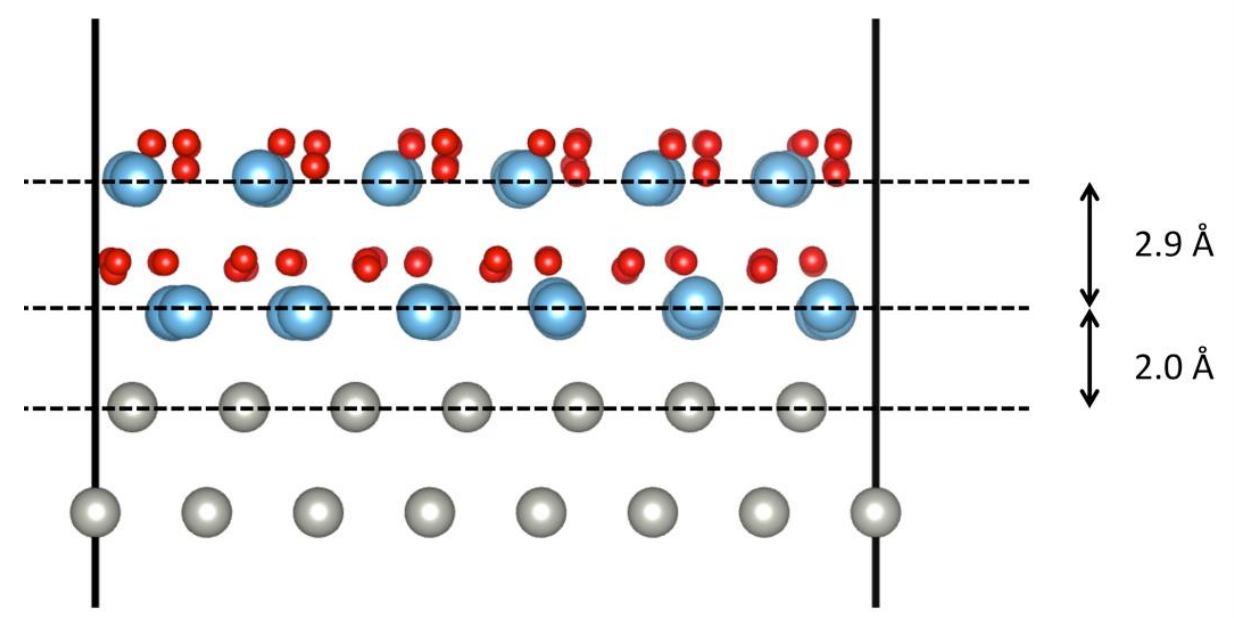

Cross section of super cell in which the orientation of k-phase and $\operatorname{Pd}(111)$ agrees with the experimental cross section.

\section{Testing overlayers that include hydrogen}

We have studied hydrogenated k-phase single- and double layers with one, two or three $\mathrm{H}$ atoms per unit cell, where hydrogen binds to the bridging oxygens, forming hydroxyl groups. This corresponds to coverages of $1 / 3,2 / 3$ and 1 in terms of the available oxygen atoms. Calculations have been carried out in the $(1 \times 1) /(2 \times 2)$ supercells and since hydrogen adsorption was generally found to be unstable, we did not investigate other supercells. The Figure below shows the stability of the hydrogenated single and double layers. We have assumed a constant hydrogen partial pressure of 0.05 bar. This way the hydrogenated phases have the same slope of formation free energies with respect to the chemical potential of oxygen. The unit cell of the hydrogenated single layers is included for illustration. All hydrogenated overlayers are instable with respect to the bare overlayers and become increasingly unstable with higher H-coverage. 


\section{Figure S19}

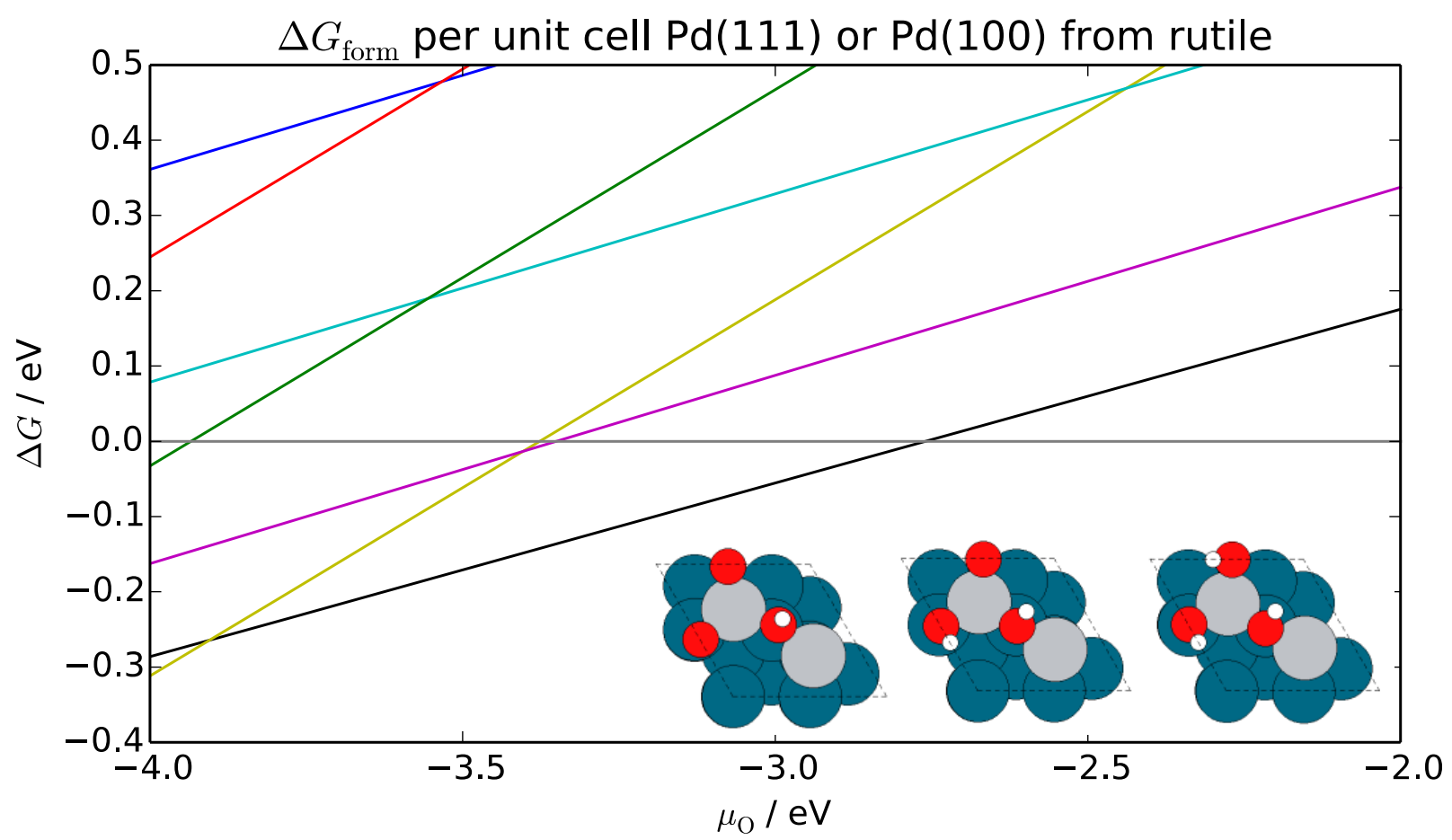

Stability of hydrogenated single and double layers. Structural models are shown in an inset.

\section{Overlayers on Pd(100)}

Forming supercells with low lattice mismatch is more challenging since the minimal unit cell of $\mathrm{Pd}(100)$ is cubic and that of the $\mathrm{k}$-phase is hexagonal. We have therefore generated a rectangular k-phase unit cell, which fits best onto a $(2 \times 5)-\mathrm{Pd}(100)$ supercell. In the same way, we have generated a supercell with the hexagonal $\mathrm{TiO}$ structure on $\operatorname{Pd}(100)$. Additionally, we found a cubic structure that it is stable at low $\mu_{0}$. This cubic structure is the analagon to rocksalt(111)/Pd(111) for $\mathrm{Pd}(100)$ : It is a continuation of the fcc(100) facet with one layer of Ti and one layer of oxygen. 
Figure S20

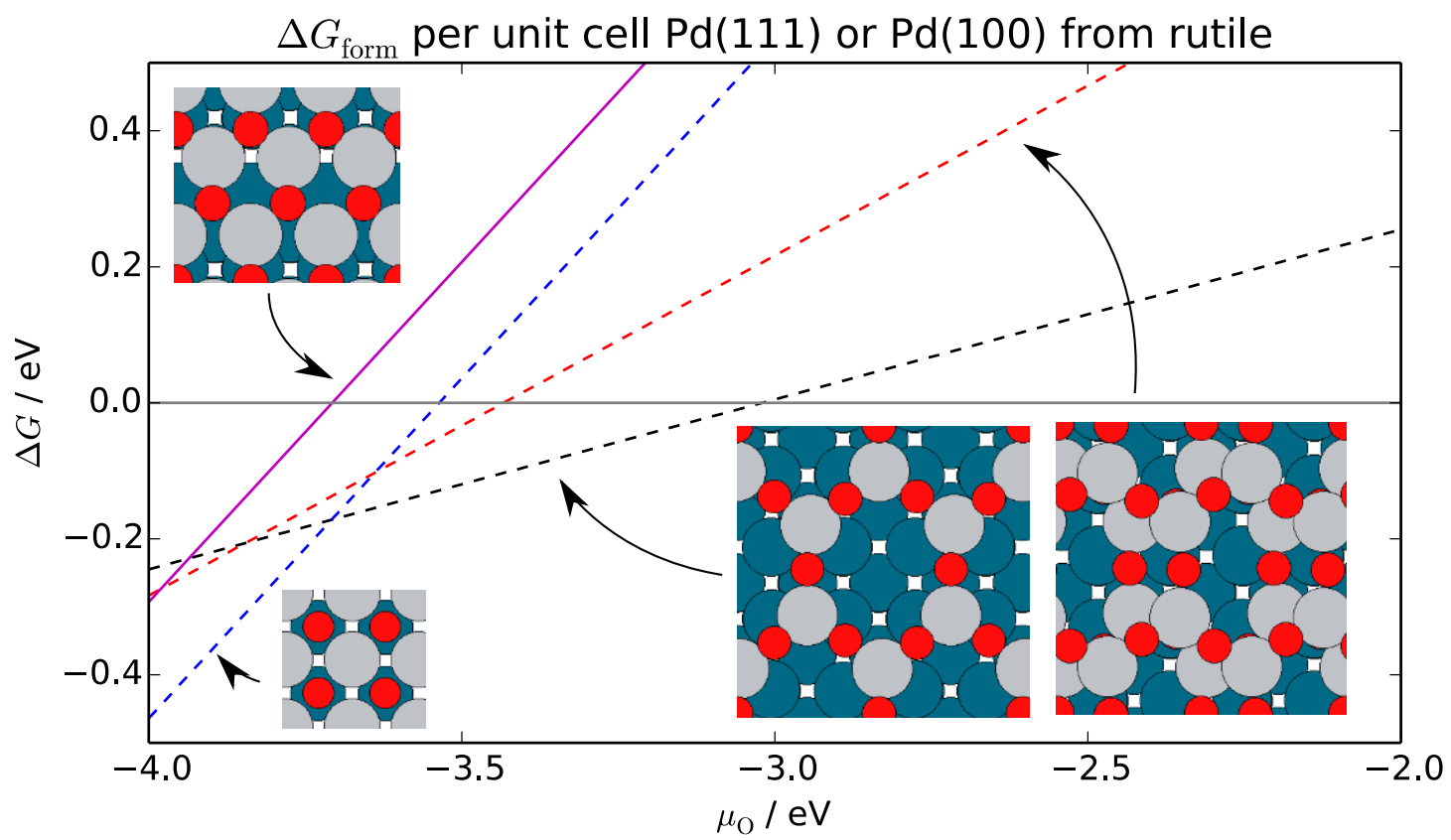

$$
\begin{array}{lllll}
--- & \text { 001-k-phase }\left(\mathrm{Ti}_{2} \mathrm{O}_{3}\right) & - & 001-\mathrm{TiO}_{-} \text {rocksalt } \\
--- & 001-k 2 / 1 x 4 & ---p & \text { 001-TiO_cubic } \\
\end{array}
$$

Stability of $\operatorname{Pd}(100)$-supported layers. Structural models are shown in an insets.

\section{Cartesian coordinates of the most relevant structures}

Structures of the overlayers discussed in the main article are given in the .cif format below.

100-Monolayer

$$
\begin{aligned}
& \text { data_image0 } \\
& \text { _cell_length_a } 5.58418 \\
& \text { _cell_length_b } 11.1684 \\
& \text { _cell_length_c } 24.6238 \\
& \text { _cell_angle_alpha } 90 \\
& \text { _cell_angle_beta } 90 \\
& \text { _cell_angle_gamma } 90
\end{aligned}
$$

loop_

_atom_site_label 


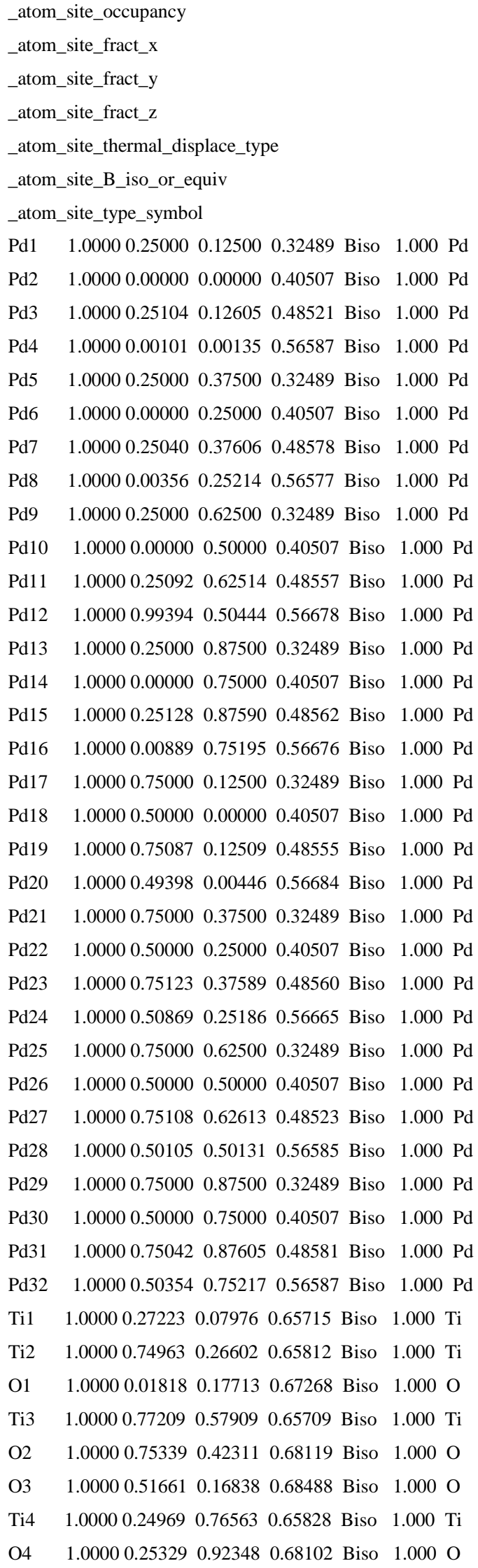


$\begin{array}{llllllll}\text { O5 } & 1.0000 & 0.51761 & 0.67620 & 0.67278 & \text { Biso } & 1.000 & \mathrm{O} \\ \text { O6 } & 1.0000 & 0.01809 & 0.66651 & 0.68478 & \text { Biso } & 1.000 & \mathrm{O}\end{array}$

Monolayer, $(\sqrt{3} \times \sqrt{3})-\mathrm{R} 30^{\circ} /(\sqrt{13} \times \sqrt{13})-\mathrm{R} 14^{\circ}$

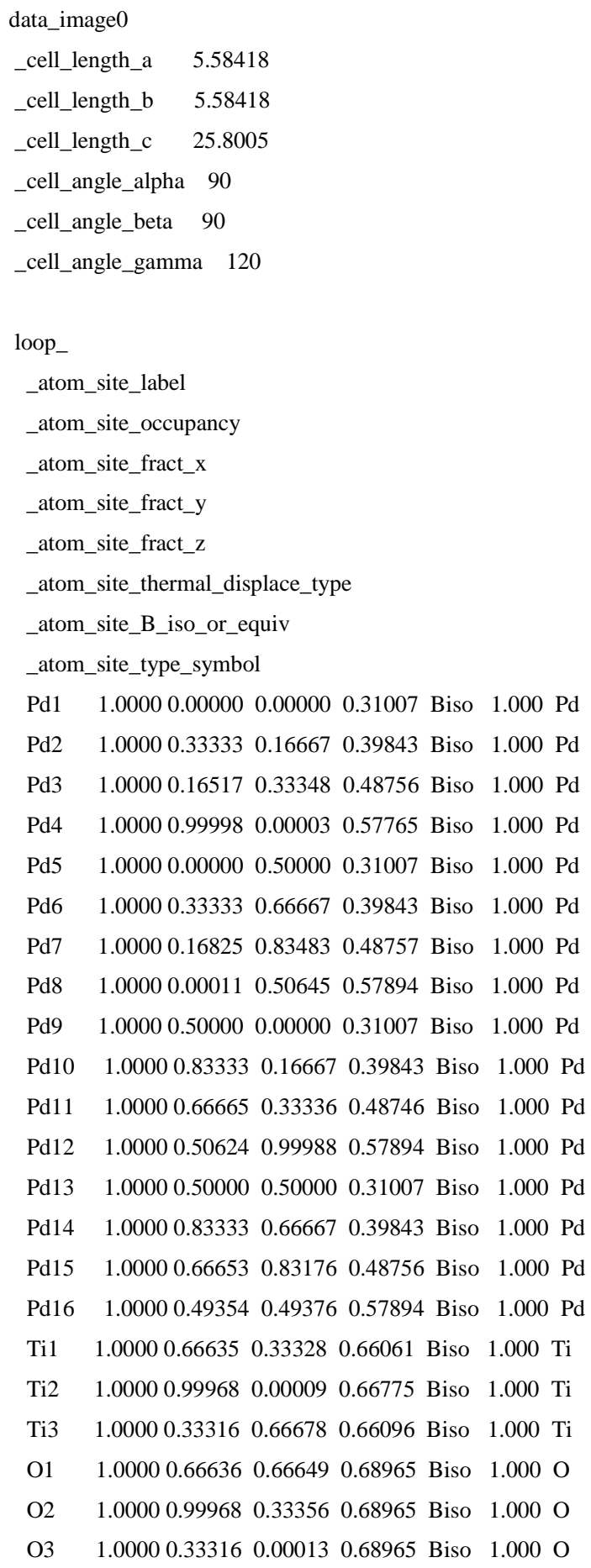

Doublelayer, $(\sqrt{ } 3 \times \sqrt{ } 3)-\mathrm{R} 30^{\circ} /(\sqrt{13} \times \sqrt{13})-\mathrm{R} 14^{\circ}$ 


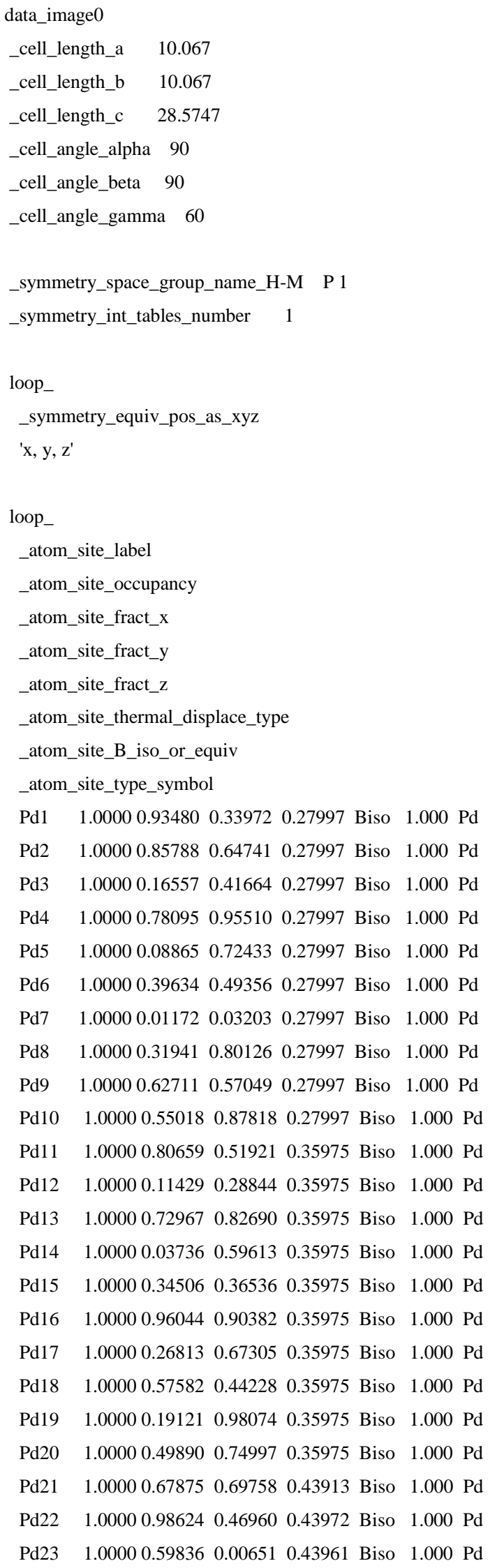




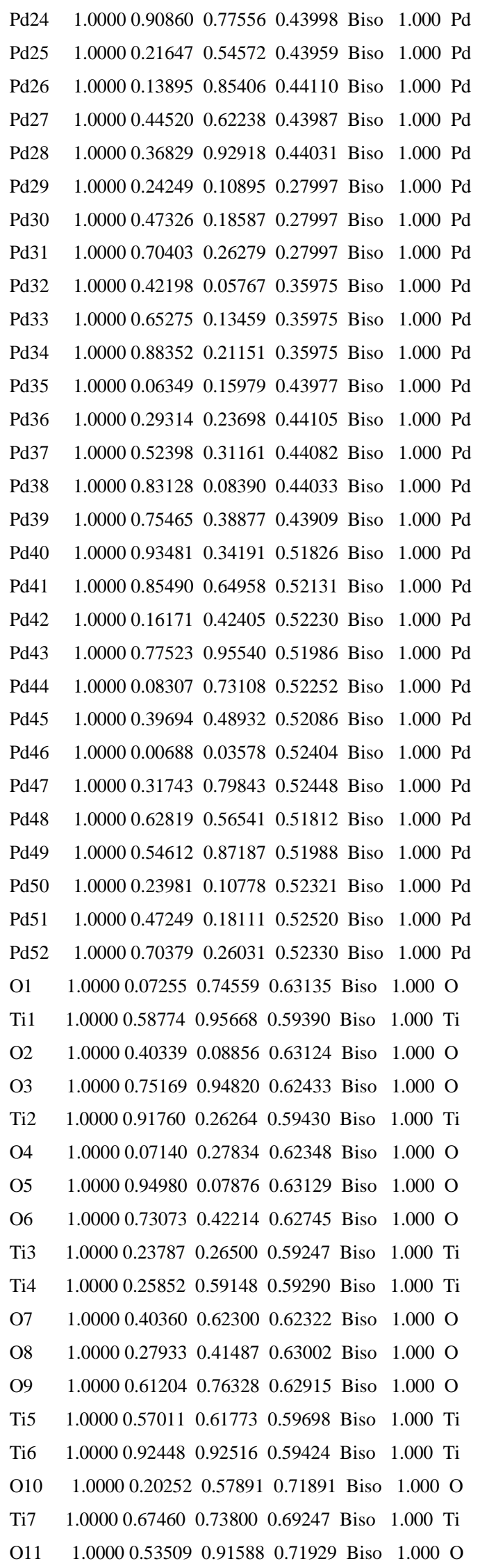




\begin{tabular}{|c|c|c|c|c|c|}
\hline & & & & & 1.000 \\
\hline & .00000 .00784 & & 0.69428 & Biso & 1.000 \\
\hline & 1.00000 .20296 & 0.02828 & 0.70119 & 9 Biso & 1.000 \\
\hline 14 & 1.00000 .98764 & 0.91351 & 0.72003 & 3 Biso & 1.000 \\
\hline 015 & 1.00000 .86464 & 0.25162 & 0.71738 & 8 Biso & 1.000 \\
\hline & 1.00000 .35903 & 0.06735 & 0.69382 & Biso & 1.000 \\
\hline $\mathrm{i} 10$ & 1.00000 .34077 & 0.39844 & 0.69279 & Biso & 1.000 \\
\hline $\mathrm{O} 16$ & 1.00000 .53646 & 0.36022 & 0.69861 & 1 Biso & 1.000 \\
\hline $\mathrm{O} 17$ & 1.00000 .31859 & 0.24742 & 0.71956 & 6 Biso & 1.000 \\
\hline 018 & 1.00000 .64719 & 0.58542 & 0.71549 & 9 Biso & 1.000 \\
\hline i11 & 1.00000 .69016 & 0.40226 & 0.69129 & Biso & 1.000 \\
\hline i1 & 1.00000 .02722 & 0.73283 & 0.69417 & Biso & 1.000 \\
\hline
\end{tabular}

\section{1: TiO-rocksalt(111)}

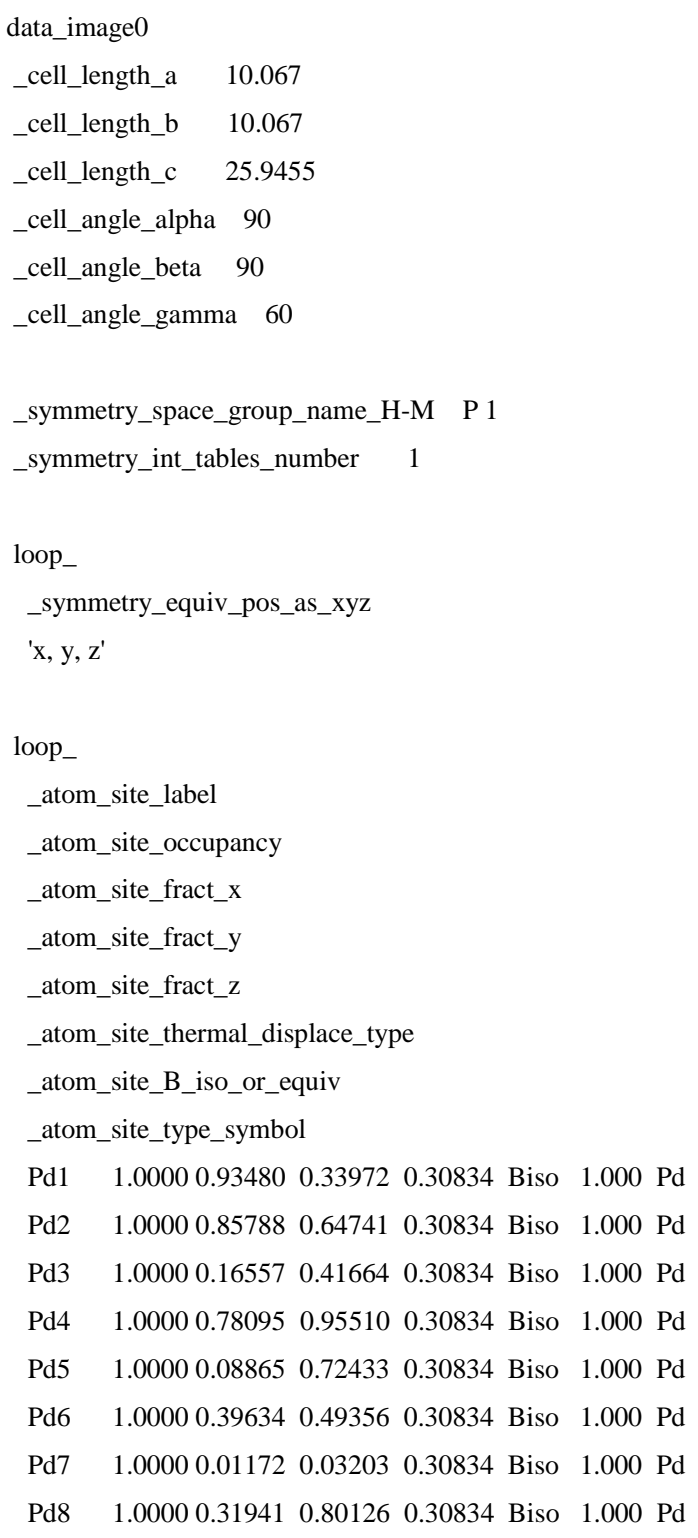




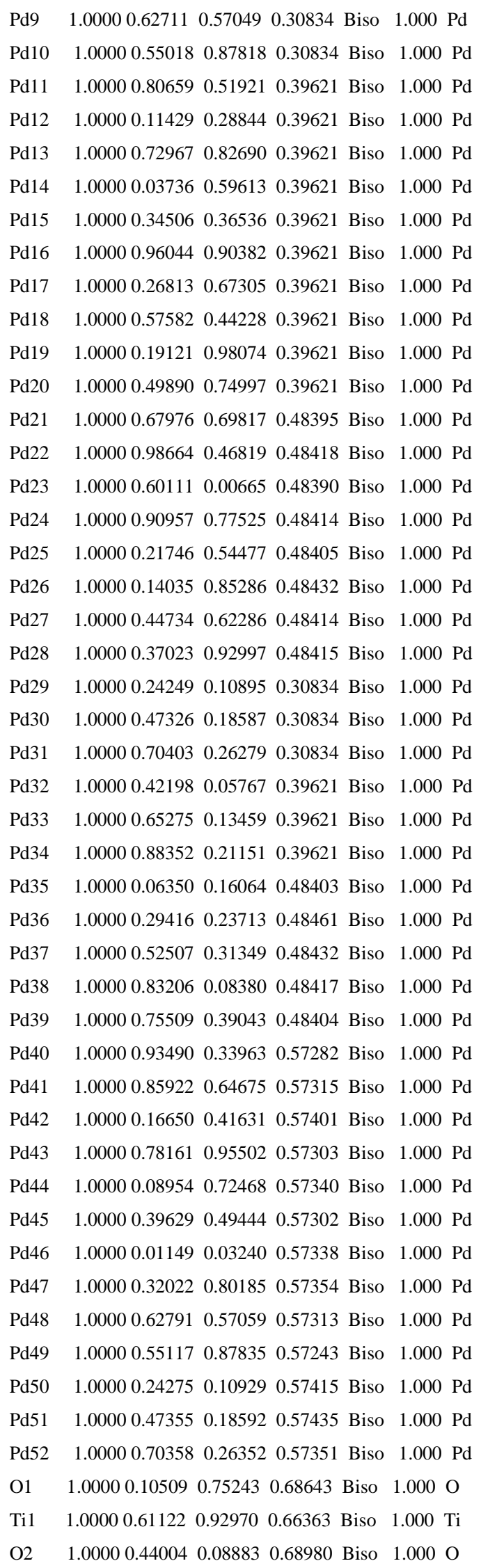




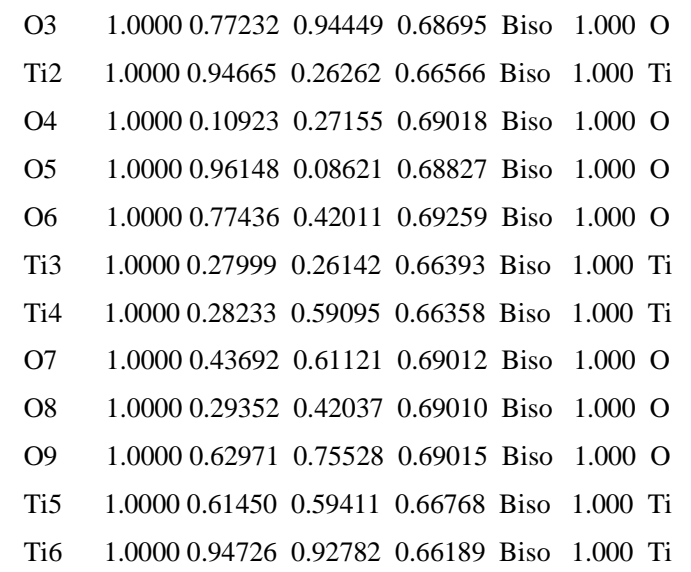

\section{0-Doublelayer}

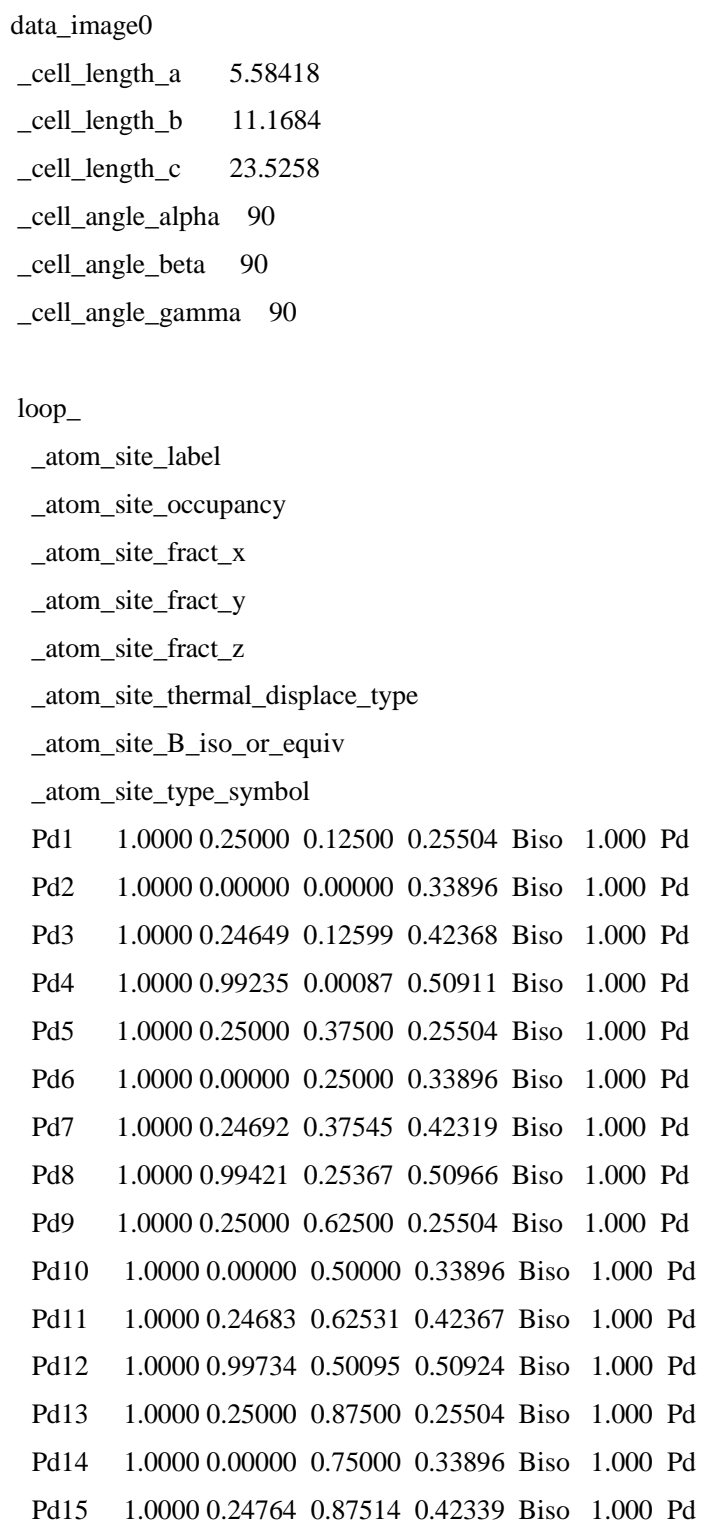




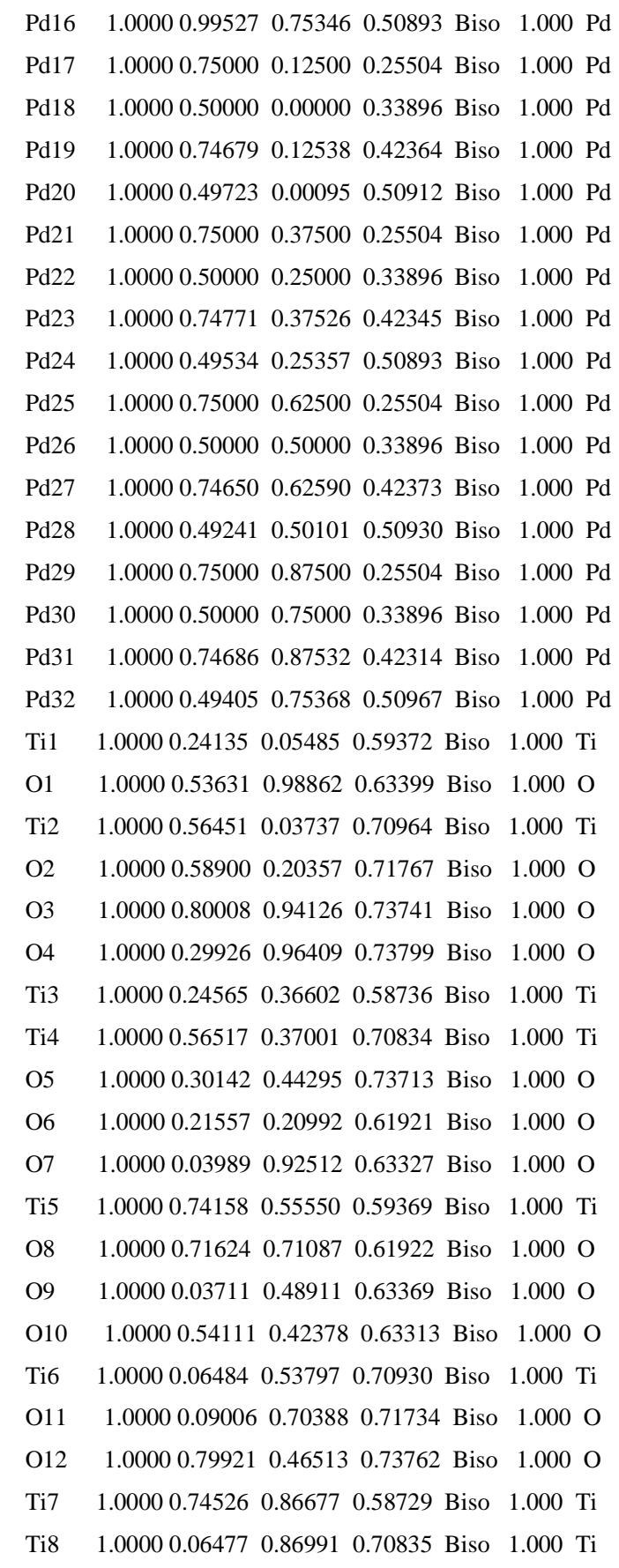




\section{References}

1. Cargnello, M.; Doan-Nguyen, V. V.; Gordon, T. R.; Diaz, R. E.; Stach, E. A.; Gorte, R. J.; Fornasiero, P.; Murray, C. B. Science 2013, 341, 771-773.

2. $\quad$ Peng, S.; Lee, Y.; Wang, C.; Yin, H.; Dai, S.; Sun, S. Nano research 2008, 1, 229-234.

3. Zhang, S.; Chen, C.; Cargnello, M.; Fornasiero, P.; Gorte, R. J.; Graham, G. W.; Pan, X. Nature communications 2015, 6, 8778.

4. Giannozzi, P.; Baroni, S.; Bonini, N.; Calandra, M.; Car, R.; Cavazzoni, C.; Ceresoli, D.; Chiarotti, G. L.; Cococcioni, M.; Dabo, I. J. Phys.: Condens. Matter 2009, 21, 395502.

5. $\quad$ Vanderbilt, D. Physical Review B 1990, 41, 7892-7895.

6. $\quad$ Bengtsson, L. Physical Review B 1999, 59, 12301-12304.

7. Dulub, O.; Hebenstreit, W.; Diebold, U. Phys. Rev. Lett. 2000, 84, 3646.

8. Barcaro, G.; Sedona, F.; Fortunelli, A.; Granozzi, G. The Journal of Physical Chemistry C 2007, 111, 6095-6102.

9. $\quad$ Batson, P. E. Microsc. Microanal. 2008, 14, 89-97.

10. Krivanek, O. L.; Dellby, N.; Murfitt, M. F.; Chisholm, M. F.; Pennycook, T. J.; Suenaga, K.; Nicolosi, V. Ultramicroscopy 2010, 110, 935-945.

11. Chi, M.; Wang, C.; Lei, Y.; Wang, G.; Li, D.; More, K. L.; Lupini, A.; Allard, L. F.; Markovic, N. M.; Stamenkovic, V. R. Nature communications 2015, 6, 8925.

12. Lupini, A.; Krivanek, O.; Dellby, N.; Nellist, P.; Pennycook, S. In Developments in $C \sim$ s-corrected STEM, CONFERENCE SERIES-INSTITUTE OF PHYSICS, 2001; Philadelphia; Institute of Physics; 1999: pp 31-34. 